This is a pre-copyedited, author-produced PDF of an article accepted for publication in Boundary-Layer Meteorology following peer review.

The version of record [Arduini, G., Staquet, C \& Chemel, C., 'Interactions between the night time valley-wind system and a developing cold-air pool', Boundary-Layer Meteorol (2016) 161:1 (49-72), first published online June 2, 2016, is available at Springer online at doi: 10.1007/s10546-016-0155-8 
G. Arduini (四)

Université Grenoble Alpes, LEGI, F-38000, Grenoble, France

e-mail: gabriele.arduini@legi.grenoble-inp.fr

G. Arduini

CNRS, LEGI, F-38000, Grenoble, France

\section{G. Arduini}

Centre for Atmospheric \& Instrumentation Research, University of Hertfordshire, College Lane, Hatfield, AL10 9AB, UK

e-mail: g.arduini@herts.ac.uk

C. Staquet

Université Grenoble Alpes, LEGI, F-38000, Grenoble, France

C. Staquet

CNRS, LEGI, F-38000, Grenoble, France

C. Chemel

National Centre for Atmospheric Science (NCAS), Centre for Atmospheric \& Instrumentation Research, University of Hertfordshire, College Lane, Hatfield, AL10 9AB, UK 
cold-air pool and its evolution are found to be independent of the valley length as soon as the quasi-steady state is reached and the down-valley flow is fully developed.

Keywords Cold-air pool · Downslope flow $\cdot$ Numerical simulation

\section{Introduction}

The representation of the stable atmospheric boundary layer in complex terrain, ranging from rugged lowlands with valley incisions to the highest mountains, constitutes a significant forecasting challenge. Small-scale processes in such complex terrain remain largely unresolved by current numerical weather prediction models and so are their impacts on weather, climate and air quality (see for instance Zardi and Whiteman 2013). Specifically, large temperature variations may occur over short distances, especially during clear nights when radiative cooling of the surface leads to a strong ground-based inversion (GBI). In areas sheltered from the atmosphere above, particularly from flow where high wind speeds and consequent intense turbulent mixing conspire to reduce vertical temperature gradients towards zero (e.g. Vosper and Brown 2008; Lareau and Horel 2015), or under quiescent synoptic conditions, cold-air pools (CAPs) form. CAPs are associated with a strong GBI, and so weather hazards and pollution episodes are more likely in CAPs than over flat terrain in the same region, especially when they are intense, shallow and long lasting as this may occur in winter.

Under these conditions, thermally-driven slope and valley winds are key to maintaining some degree of ventilation (e.g. Largeron 2010; Nadeau et al. 2012). Slope flows develop as a result of the horizontal thermal imbalance between the layer of air adjacent to the slope and the air at the same altitude far from the slope. At night, the radiative cooling of the ground produces downslope flows. Along-valley flows are also thermally driven and are triggered by the thermal imbalance in the down-valley direction, for instance between the valley interior and an adjacent plain.

The role of downslope flows in CAP formation under decoupled conditions depends on the scales of the terrain. Burns and Chemel $(2014,2015)$ and Vosper et al. (2014) discussed results from numerical model simulations of the formation of a CAP in valleys of very different depths. Vosper et al. (2014) considered the Clun Valley, England, a narrow valley with depth between 75 and $150 \mathrm{~m}$. In such a shallow valley, the sheltering provided by surrounding terrain allowed a CAP to form. The strong atmospheric static stability of the simulated developing CAP rapidly suppressed downslope flows. The cooling of the air adjacent to the ground was dominated by parametrized subgrid-scale (SGS) turbulent mixing, while the cooling above was dominated by transport of cold air from the valley sides or from down-valley drainage. By contrast, Burns and Chemel $(2014,2015)$ considered an idealized $1-\mathrm{km}$ deep narrow valley, not subject to down-valley winds. In such a deep valley, downslope flows were found to play a major role in the development of a CAP. As the cold-air region engulfed the slopes, a 100-m deep strongly stratified GBI was left above the valley floor. The downslope flows then detrained largely above the GBI layer, thereby mixing the upper part of the CAP. The valley-atmosphere instantaneous cooling was eventually driven by a complex interplay between radiative cooling and dynamical cooling.

Although widely observed (e.g. Neff and King 1987; Banta et al. 2004; Pinto et al. 2006; Schmidli et al. 2009), the influence of down-valley flows on the evolution of CAPs under decoupled conditions is not well characterized, presumably owing to the challenges in simulating CAPs (Baker et al. 2011) and collecting extensive observations. Numerical modelling studies investigating CAP processes have generally considered two-dimensional (2D) 
valley geometries that are invariant in the down-valley direction (referred to as $2 \mathrm{D}$ valleys hereafter), thereby preventing any thermally-driven down-valley flow from developing (e.g. Vosper and Brown 2008; Catalano and Cenedese 2010; Katurji and Zhong 2012; Burns and Chemel 2014, 2015). Numerical simulations considering valleys with a three-dimensional (3D) geometry that is varying in the down-valley direction (referred to as 3D valleys hereafter) have generally focussed on convective situations (e.g. Rampanelli et al. 2004; Schmidli et al. 2011). Only a few studies have examined pooling and draining processes in 3D valleys. Zängl (2005) investigated processes promoting the formation of extreme CAPs in an idealized elevated sinkhole (i.e., closed basin). O'Steen (2000) examined the impact of tributaries on the nighttime down-valley flow and on the associated mass transport outside idealized valleys. Schmidli and Rotunno (2010) examined the mechanisms leading to the formation of a thermally-driven along-valley flow in a $3 \mathrm{D}$ valley. The importance of the geometry of the valley with respect to the other mechanisms in the development of a valley-plain temperature difference, was quantified using the concept of a topographic amplification factor (see, for instance, Whiteman 1990). Results indicated that the along-valley flow induce a heating of the valley atmosphere during the night and a cooling of the valley atmosphere during the day. Similar conclusions were reported during daytime by Rampanelli et al. (2004) in a study of an idealized valley, and by Weigel et al. (2006) in a real-case study of the Riviera Valley in southern Switzerland. For nocturnal conditions, the heating of the valley atmosphere was explained by subsidence motions from the atmosphere above the valley, due to the divergence of the down-valley flow.

The overall aim of the present work is to characterize the influence of a thermally-driven down-valley flow on a developing CAP in an idealized alpine valley under decoupled conditions. For this purpose, we analyze and compare results from numerical model simulations of a developing CAP in a 3D valley and in the counterpart 2D valley. The set-up of the numerical simulations is presented in Sect. 2, and the development of the thermally-driven down-valley flow is discussed in Sect. 3. In Sect. 4, the influence of the down-valley flow is quantified by contrasting the $3 \mathrm{D}$ and $2 \mathrm{D}$ valley cases, and in Sect. 5 we investigate the sensitivity of the results to the valley length. Finally, conclusions are given in Sect. 6.

\section{Design of the numerical simulations}

\subsection{The numerical model}

The numerical simulations were performed with the Weather Research and Forecasting (WRF) model, in its version 3.4.1 of the Advanced Research core formulation (Skamarock et al. 2008). The WRF model is a compressible non-hydrostatic model, appropriate for scales ranging from metres to global scales. The governing equations are formulated using a terrainfollowing hydrostatic-pressure coordinate and discretized on a staggered Arakawa-C grid. For the present work, time integration was performed with a third-order Runge-Kutta scheme using a time-splitting technique to integrate the fast acoustic mode (Wicker and Skamarock 2002). The advection terms were discretized using a fifth-order Weighted Essentially NonOscillatory (WENO) scheme with positive definite filter. The planetary boundary layer was not parametrized and SGS motions were modelled with a standard turbulent kinetic energy 1.5-order closure scheme, with the Smagorinsky coefficient $C_{s}$ set to 0.1 . We note that in a stably stratified atmosphere, $C_{S}$ may vary with height (Smith and Porté-Agel 2014), limiting or enhancing SGS mixing. Dynamical models (see for instance Bou-Zeid et al. 2004; Smith and Porté-Agel 2014) allow the variation of $C_{s}$ with height, depending on the instantaneous 

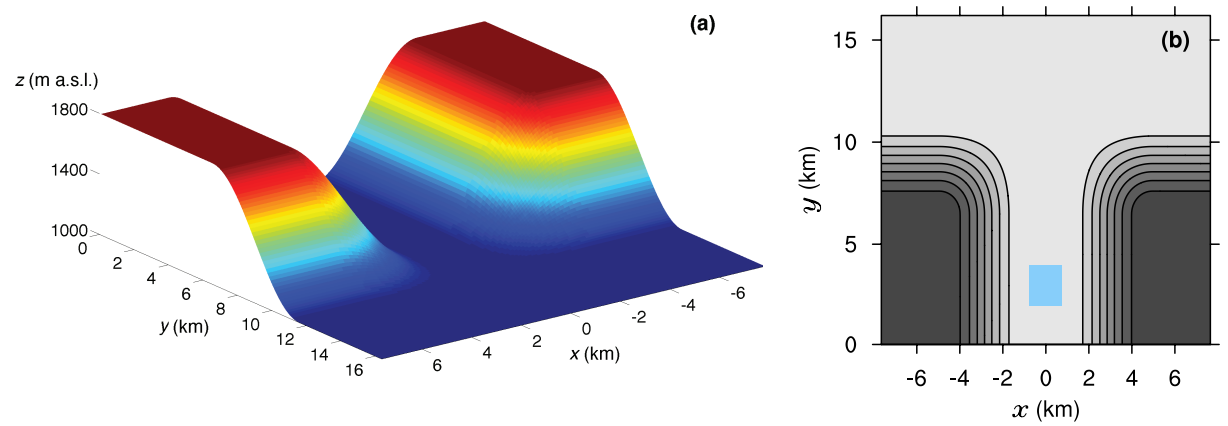

Fig. 1 (a) Terrain height for the control case. The topography is symmetric about the origin $(x, y)=(0,0)$, where the cross-valley direction $x$ is oriented west-east and the down-valley direction $y$ is oriented south-north. (b) Contours of the terrain height (with intervals of $100 \mathrm{~m}$ ) for the control case; the light blue box denotes the valley centre area, i.e. the area within the valley defined by $2<y<4 \mathrm{~km}$ and $|x| \leq L_{x}$; see Sect. 2.6 for details. Note that half of the topography along the $y$-direction is displayed.

flow characteristics. The effect of these variations on the motion at the resolved scales, need to be quantified in future work. Radiative transfer was taken into account using the Rapid Radiative Transfer Model for longwave radiation (Mlawer et al. 1997) and the scheme proposed by Dudhia (1989) for shortwave radiation. Shadowing effects were not included, as in Burns and Chemel (2014). The interactions with the ground surface were modelled using the community Noah Land Surface Model (Chen and Dudhia 2001) using four soil layers.

\subsection{The topography of the valley}

A valley similar to the one used by Schmidli et al. (2011) is considered. It is symmetric about the origin at $x=0$ and $y=0$ (see Fig. 1), and the analytical expression for the height of the terrain is given by

$$
h(x, y)=H h_{x}(x) h_{y}(y)+h_{0},
$$

where

$$
h_{x}(x)= \begin{cases}{\left[1-\cos \left(\pi\left(|x|-L_{x}\right) / S_{x}\right)\right] / 2} & \text { for } L_{x} \leq|x| \leq S_{x}+L_{x} \\ 0 & \text { for }|x|<L_{x} \\ 1 & \text { for }|x|>S_{x}+L_{x}\end{cases}
$$

and

$$
h_{y}(y)=\left\{\begin{array}{ll}
{\left[1+\cos \left(\pi\left(|y|-L_{y}\right) / S_{y}\right)\right] / 2} & \text { for } L_{y}<|y| \leq S_{y}+L_{y} \\
0 & \text { for }|y|>L_{y}+S_{y} \\
1 & \text { for }|y| \leq L_{y}
\end{array} .\right.
$$

The topography considered is characterized by a valley depth $H=800 \mathrm{~m}$, a width of the sloping sidewalls $S_{x}=4200 \mathrm{~m}$ (in the cross-valley direction $x$ ) and $S_{y}=5000 \mathrm{~m}$ (in the down-valley direction $y$ ) and a half-width of the valley floor $L_{x}=750 \mathrm{~m}$ (in the cross-valley direction $x$ ). The reference height is set to $h_{0}=1000 \mathrm{~m}$. With this setup, the maximum angle $\alpha$ of the slope is about $17^{\circ}$. The length of the valley $L_{y}$ (as displayed in Fig. 1) is varied from 6 to $10 \mathrm{~km}$, with $L_{y}=6 \mathrm{~km}$ for the control case. The total valley length $L_{\text {tot }}=L_{y}+S_{y}$ for the control case is then equal to $11 \mathrm{~km}$. All the model points were assigned the latitude and longitude of the centre of the Chamonix valley located in the French Alps. 


\subsection{Grid design}

Burns and Chemel (2014) have shown that a vertical resolution smaller than a few metres is needed to capture the downslope flows and the structure of the valley boundary layer. Furthermore, the modelling studies by Rampanelli et al. (2004) and Schmidli et al. (2011) have shown that the domain should be large enough for the flow dynamics not to be influenced by the lateral boundary conditions. To satisfy these constraints, we relied on the nesting capability of the WRF model. Two domains were used: an outer domain (D1) discretized with $114 \times 334 \times 101$ grid points in the $x$-, $y$ - and $z$-direction, respectively, with a horizontal resolution $\left.\Delta x\right|_{\mathrm{D} 1}=\left.\Delta y\right|_{\mathrm{D} 1}=270 \mathrm{~m}$, and an inner domain (D2) discretized with $172 \times 361 \times 101$ grid points in the $x$-, $y$ - and $z$-direction, respectively, with a horizontal resolution $\left.\Delta x\right|_{\mathrm{D} 2}=\left.\Delta y\right|_{\mathrm{D} 2}=90 \mathrm{~m}$, both centered on the origin. The nesting between the two domains is one-way, in the sense that the boundary conditions of the inner domain are updated from the outer domain solution every outer-domain timestep, with no feedback from the inner domain on the outer domain.

The vertical coordinate was stretched along the vertical direction using a hyperbolic tangent function (Vinokur 1980), providing a vertical resolution $\Delta z \approx 1.7 \mathrm{~m}$ for the first level above the ground surface, and 10 levels in the first $20 \mathrm{~m}$ above the ground surface. In order to obtain numerically stable results, the vertical grid resolution demanded a timestep $\left.\Delta t\right|_{\mathrm{D} 2}=0.15 \mathrm{~s}$ for the inner domain, and a timestep $\left.\Delta t\right|_{\mathrm{D} 1}=0.45 \mathrm{~s}$ for the outer domain.

It is acknowledged that the grid resolution is too coarse to resolve the full range of turbulent motions acting in stable boundary layers and the numerical simulation performed in this work shall be referred to as high-resolution mesoscale simulations (Cuxart 2015).

\subsection{Initial conditions}

The simulations were initialized $1 \mathrm{~h}$ before sunset, and were run for a 6-h period. Decoupled conditions were considered and so no flow was prescribed at the initial time $(t=0)$. The atmosphere was initialized to be in hydrostatic balance. The vertical lapse rate of virtual potential temperature $\partial \theta_{v} / \partial z$ at $t=0$ was set to $1.5 \mathrm{~K} \mathrm{~km}^{-1}$, yielding a temperature profile typical of post-convective conditions. For simplicity, $\theta_{v}$ is referred to as potential temperature thereafter. The Brunt-Väisäla frequency $N=\sqrt{\left(g / \theta_{v}\right)} \partial \theta_{v} / \partial z$, where $g$ is the acceleration due to gravity, has then an initial value $N_{0} \approx 0.7110^{-2} \mathrm{~s}^{-1}$ within the valley. The potential temperature of the first air layer at the valley floor was set to $\theta_{0}=288 \mathrm{~K}$, and the skin temperature was initialized by extrapolating the temperature of the first three air layers above the ground surface. A detailed discussion of the soil initialization is given in Burns and Chemel (2014). The atmosphere was initialized with a relative humidity of $40 \%$.

\subsection{Boundary conditions}

Lateral boundary conditions for the outer domain were set to periodic boundary conditions in the $x$-direction and to open boundary conditions in the $y$-direction. The total height of the domain is $12 \mathrm{~km}$. A 4-km deep implicit Rayleigh sponge layer (Klemp et al. 2008) was used at the top of the domain to damp upward propagating gravity waves; the damping coefficient was set to $0.2 \mathrm{~s}^{-1}$. At the ground the usual impermeability condition was used, together with the Monin-Obukhov similarity theory, which was applied as the bottom boundary condition for the turbulent fluxes. We note that a slope-modified similarity theory (see for instance 
Łobocki 2014) may be more appropriate to represent the surface layer of a sloping surface. The aerodynamic roughness length was set to $0.1 \mathrm{~m}$.

\subsection{Definition of control volumes}

Since the valley boundary layer coincides with the CAP, it will be referred to as CAP thereafter. Following Burns and Chemel (2015), the CAP is decomposed in two parts: the GBI, defined as the layer of atmosphere above the ground surface where a temperature inversion develops (that is $\partial T / \partial z>0$, where $T$ is the absolute temperature), and the part of the CAP above the GBI, which will be referred to as CAP $\uparrow$.

The height of the GBI, denoted by $z_{\mathrm{GBI}}$, is defined as the height where the absolute temperature ceases to increase with height. When the atmosphere is not dry, Burns and Chemel (2015) have shown that the height of the top of the humid layer can be used to track accurately the top of the CAP, denoted by $z_{\mathrm{CAP}}$; we use this definition hereafter. Note that a more standard definition of the height of the CAP, based on the height where the vertical gradient of potential temperature reaches a maximum, will also be used; this definition can be equivalently expressed in terms of the height where the Brunt-Väisäla frequency reaches a maximum value.

Different spatial averages will be considered below. We consider the average over the area defined by $|x| \leq L_{x}$ (i.e. the width of the valley floor) and $2 \leq y \leq 4 \mathrm{~km}$ (where the plateaux are flat and the slope angle does not change along the down-valley direction, see Fig. 1b), which will be referred to as the valley centre area hereafter and, for clarity, will be written in italics when referring to this area. Volume averages will be performed over along-valley sections defined by $2 \leq y \leq 4 \mathrm{~km}$ and of height range corresponding to the GBI or CAP $\uparrow$. These volumes will be referred to as the GBI volume and the $\mathrm{CAP} \uparrow$ volume, respectively.

\subsection{Definition of a counterpart two-dimensional valley}

The atmospheric circulation in the $3 \mathrm{D}$ valley will be compared to that developing in a $2 \mathrm{D}$ valley. The topography of the $2 \mathrm{D}$ valley is defined by Eq. 1 with $h_{y}(y)=1$. The $2 \mathrm{D}$ simulation was set up as the 3D ones except that no grid nesting was used, and periodic boundary conditions were applied at all lateral boundaries. We recall that the formation of an alongvalley flow is inhibited in the $2 \mathrm{D}$ valley.

\section{Mechanism of down-valley winds}

\subsection{Differential cooling between the valley and the plain}

Vertical profiles of the potential temperature above the valley floor and the plain are displayed at different times in Fig. 2. During the first 30 min of simulation, the vertical temperature structure in the valley is the same as over the plain (see Fig. 2a). After 90 min (i.e., $30 \mathrm{~min}$ after sunset), a shallow stable boundary layer typical of flat terrain develops over the plain; in the valley, by contrast, the boundary layer is deeper and, for a given height, displays lower temperatures than over the plain. This differential cooling is linked to the downslope 

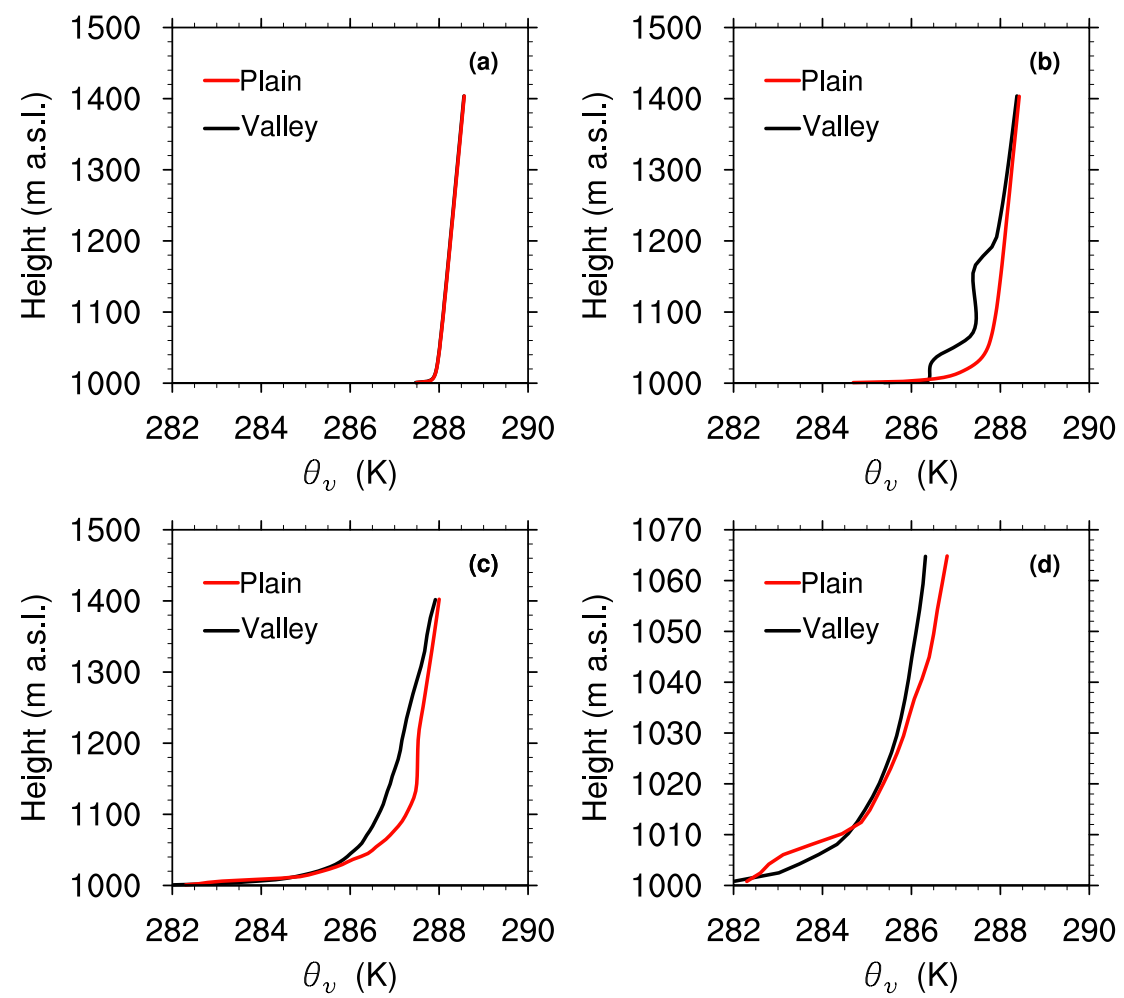

Fig. 2 Vertical profiles of potential temperature $\theta_{v}$, averaged over the valley centre (black line, see Sect. 2.6) and over the plain for $12.4 \leq y \leq 14.4 \mathrm{~km}$ (red line) at (a) $t=30 \mathrm{~min}$, (b) $t=90 \mathrm{~min}$, and (c) and (d) $t=330 \mathrm{~min}$. (d) is a zoom of (c) over the first $70 \mathrm{~m}$ above the ground surface.

flows, which develop about 30 min after sunset, as follows. The air advected by the downslope flow, together with the cold air layer over the valley floor due to longwave radiative heat loss, are mixed in the vertical by the rising motions resulting from mass conservation (see Burns and Chemel 2015, and Sect. 4.1), since the down-valley flow has hardly formed at this time.

After $330 \mathrm{~min}$, the differential cooling between the valley and the plain is maintained, except over a thin layer of $10 \mathrm{~m}$ or so, where the near-surface air temperature is lower over the plain than over the valley floor (see Fig. $2 \mathrm{c}$ and $2 \mathrm{~d}$ ). This feature is closely linked to the dynamics of the downslope and down-valley flows, which are fully developed at this time, as will be discussed in the next sections.

\subsection{Development of the down-valley flow}

The valley atmosphere far from the slope layer, may be assumed to be in hydrostatic balance as discussed for example by Rampanelli et al. (2004) and Serafin and Zardi (2011). The boundary layer being deeper and colder in the valley than over the plain (except, as already discussed, over the first ten metres above ground level, see Fig. 2c and 2d), the resulting pressure difference drives a down-valley flow from the valley to the plain. Schmidli and Rotunno (2010) showed that this pressure difference can be in part explained by the 

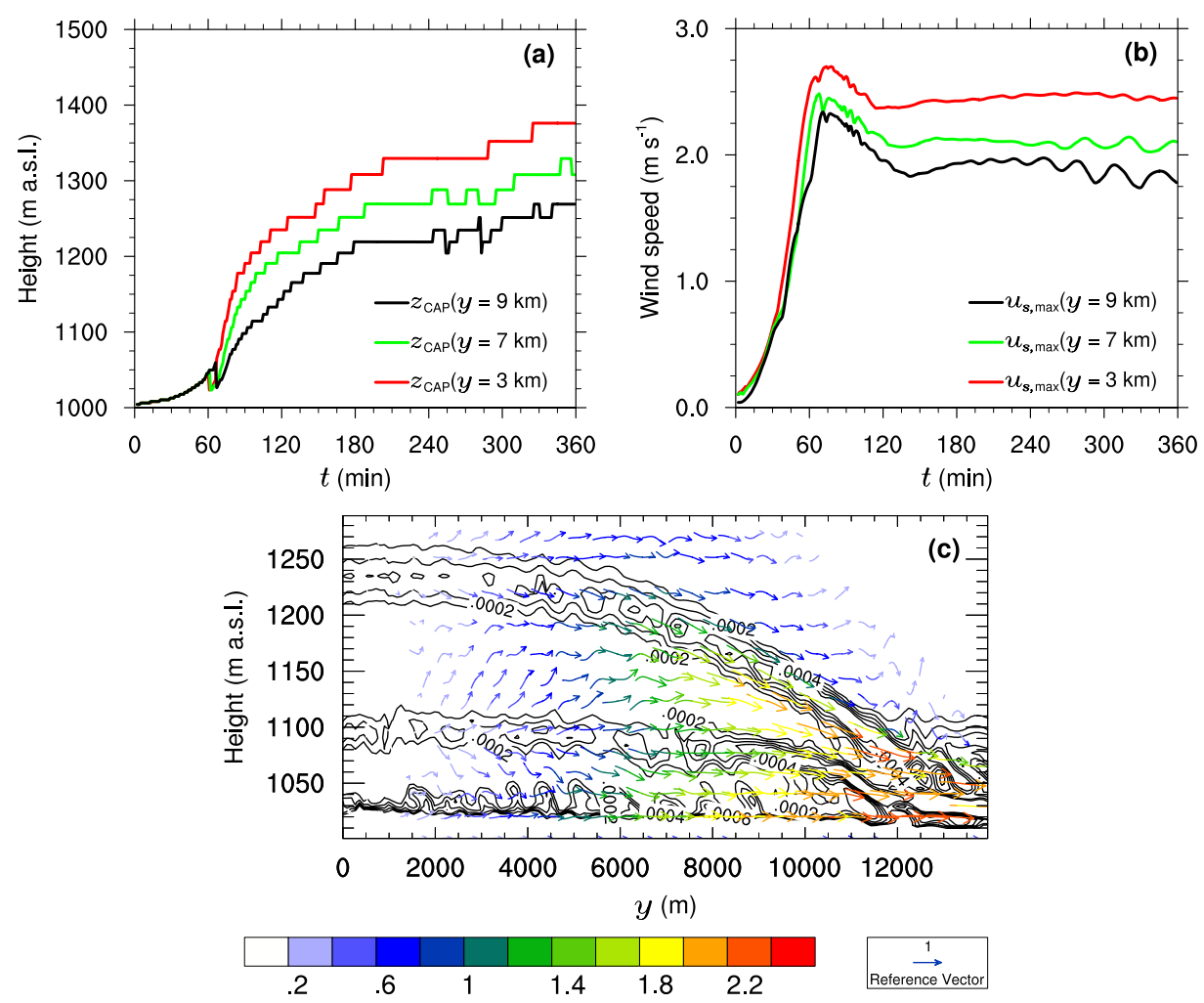

Fig. 3 Time series of (a) the height of the CAP $z_{\mathrm{CAP}}$ and (b) the maximum downslope wind speed $u_{s, \text { max }}$ at different positions in the along-valley direction $y[y=3 \mathrm{~km}$ (red lines), $y=7 \mathrm{~km}$ (green lines) and $y=9 \mathrm{~km}$ (black lines)]. (c) Along-valley cross-section of the down-valley wind vectors at $t=150$ min averaged over the width of the valley floor. The reference wind vector corresponds to $1 \mathrm{~m} \mathrm{~s}^{-1}$. Iso-contours of the square of the Brunt-Väisäla frequency $N^{2}$ averaged over the width of the valley floor are superimposed, with intervals of $10^{-4} \mathrm{~s}^{-2}$.

topographic amplification factor of the valley. In the next two sections, we investigate the role of the valley-wind system on the formation of this pressure difference.

Figure $3 \mathrm{a}$ displays the height of the CAP $z_{\mathrm{CAP}}$ versus time for different positions in the along-valley direction $y$. Since the CAP height is partly controlled by the vertical motions induced by the downslope flows, the maximum value of the downslope flow speed $u_{s, \max }$ computed at the same $y$-positions is displayed versus time in Fig. $3 b$. Figure $3 b$ shows that, until $60 \mathrm{~min}$ or so, $u_{s, \max }$ hardly varies in the y-direction. The downslope wind speed decreases from this time on, more so as the $y$-direction is closer to the valley exit. This is associated with the development of the down-valley flow after $1 \mathrm{~h}$ into the simulation (see Fig. 4). Figure $3 \mathrm{~b}$ indicates that the downslope flows reach a quasi-steady regime after about $3 \mathrm{~h}$ into the simulation. This is also the time when the along-valley flow becomes quasisteady (see Fig. 4).

Analyzing now the evolution of the CAP height, three regimes can be distinguished (see Fig. 3a). Until the time $u_{s, \max }$ reaches a maximum value, at about $60 \mathrm{~min}, z_{\mathrm{CAP}}$ hardly increases and varies in the $y$-direction. The CAP height increases sharply from this time on, due to the vertical motions induced by the downslope flows, which are more vigorous as the valley exit is farther. From $t \approx 180 \mathrm{~min}$, when the down-valley flow is fully developed 


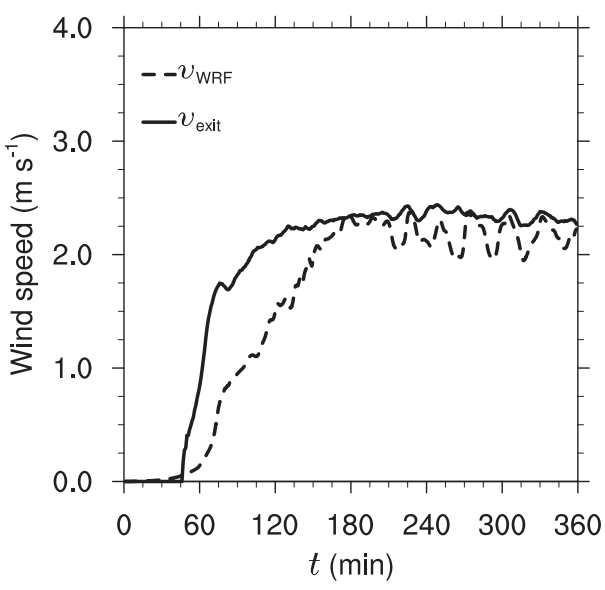

Fig. 4 Down-valley component $v$ of the wind field (dashed line) at $y=9 \mathrm{~km}$ and a height of $20 \mathrm{~m}$ above ground level, averaged over the width of the valley floor, compared to an estimate of $v$ from the Bernoulli equation (solid line, see text for details).

(i.e. a quasi-steady state is reached), the growth rate of the CAP becomes linear and nearly $y$-independent. As indicated above, $u_{s, \max }$ decreases as one moves from the valley to the plain and so does the air mass flux that contributes to the build-up of the CAP. As a result, the value reached by $z_{\mathrm{CAP}}$ after $6 \mathrm{~h}$ decreases toward the plain. This is attested by contours of the square of the Brunt-Väisäla frequency $N^{2}$ averaged over the width of the valley floor (see Fig. 3c).

Hence, the flow behaves as 'a flow in a pipe', with the cross-sectional area of the pipe set by the height of the CAP. The reduction in pressure towards the plain leads to an increase in the speed of the down-valley flow, eventually creating a jet at the valley exit. This is attested by vectors of the velocity field displayed in Fig. 3c. This result is consistent with the observations that a down-valley wind jet can persist for several $\mathrm{km}$ (e.g. Vergeiner and Dreiseitl 1987; Zängl 2004), eventually reaching a quasi-steady state (Neff and King 1989).

\subsection{A simple model for the down-valley flow}

A model for the down-valley wind component $v$ once a quasi-steady regime has been reached can be obtained from Bernoulli's equation for a steady, frictionless and irrotational fluid, viz.

$$
v_{2}=\sqrt{v_{1}^{2}+2\left(\frac{p_{1}}{\rho_{1}}-\frac{p_{2}}{\rho_{2}}\right)},
$$

where $p$ is the pressure, $\rho$ is the air density, and the subscripts 1 and 2 refer to two positions in the along-valley direction, $y_{1}$ and $y_{2}$, respectively. Equation 4 expresses that a steady state is reached with the pressure force balanced by the advection. For a position $y_{2}$ close to the valley exit, we denote $v_{2}$ by $v_{\text {exit }}$.

We computed the value of $v_{\text {exit }}$ from Eq. 4 and the WRF model outputs. For $v_{1}, p_{1}$ and $\rho_{1}$ we used the values of these fields averaged over the width of the valley floor, at a height of $20 \mathrm{~m}$ above ground level and for $y_{1}=3 \mathrm{~km}$. For $\rho_{2}$ and $p_{2}$, values at $y=9 \mathrm{~km}$ are used. The value of $v_{\text {exit }}$ is displayed in Fig. 4 versus time and compared with the numerical prediction of the down-valley wind speed at $y=9 \mathrm{~km}$ (using the same average along $x$ and for $z=20 \mathrm{~m}$ ), denoted by $v_{\mathrm{WRF}}$. Since a steady assumption is used to compute $v_{\text {exit }}$, this theoretical prediction should be compared to the numerical finding once the quasi-steady state is 


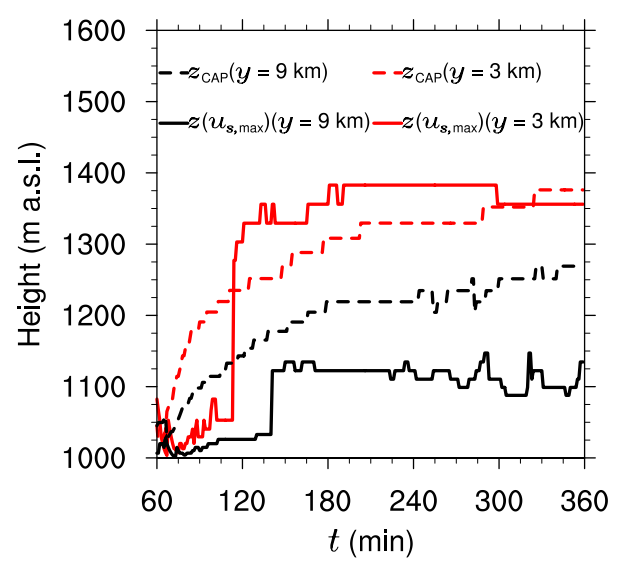

Fig. 5 Time series of the height of the maximum downslope wind speed $z\left(u_{s, \max }\right)$ (dashed lines) and the height of the CAP $z_{\mathrm{CAP}}$ (solid lines) at two positions in the along-valley direction $y[y=3 \mathrm{~km}$ (red lines) and $y=9 \mathrm{~km}$ (black lines)].

reached (after $180 \mathrm{~min}$ ). Figure 4 shows that both values agree well, $v_{\text {exit }}$ overestimating the mean (temporally averaged) value of $v_{\mathrm{WRF}}$ by about $10 \%$. Thus, Eq. 4 is a good model for the down-valley wind speed at the valley exit.

\subsection{Along-valley variation of the downslope flows}

As shown in Fig. 3b, the speed of the downslope flows decreases towards the plain. Figure 5 displays time series of the height of the maximum speed of the downslope flows $z\left(u_{s, \max }\right)$ along with those of $z_{\mathrm{CAP}}$ at two positions in the along-valley direction. There is a general retreat of the downslope flows up the slopes as the CAP engulfs the slopes. This is consistent with the findings of Burns and Chemel (2015) for a 2D valley case. However, $z\left(u_{s, \max }\right)$ is always lower than $z_{\mathrm{CAP}}$ for $y=9 \mathrm{~km}$ (i.e., towards the valley exit). This can be explained as follows. Towards the valley exit, the depth of the valley is significantly shallower (about $360 \mathrm{~m}$ at $y=9 \mathrm{~km}$ ), and the downslope flows penetrate well below the height of the CAP. They reach their level of neutral buoyancy and detrain just above the GBI, located at about $100 \mathrm{~m}$ above the valley floor towards the valley exit.

\section{Impact of the down-valley flow on cold-air-pooling processes}

In the following we compare results from the $3 \mathrm{D}$ valley section defined by $2 \leq y \leq 4 \mathrm{~km}$ to those from the counterpart 2D valley.

\subsection{Changes in the vertical structure of the cold air pool}

Figure 6 displays, for different times, vertical cross-valley sections of potential temperature $\theta_{v}$ and wind vectors $\mathbf{u}_{c r} \equiv(u, w)$, where $u$ and $w$ are the components of the wind in the cross-valley direction $x$ and vertical direction $z$, respectively. Both fields are averaged over the along-valley section defined above. We recall that the down-valley flow is fully developed and reaches a quasi-steady state about $3 \mathrm{~h}$ into the simulation, that is $2 \mathrm{~h}$ after sunset (see Fig. 4). Before this time, the thermodynamics of the valley atmosphere is qualitatively 

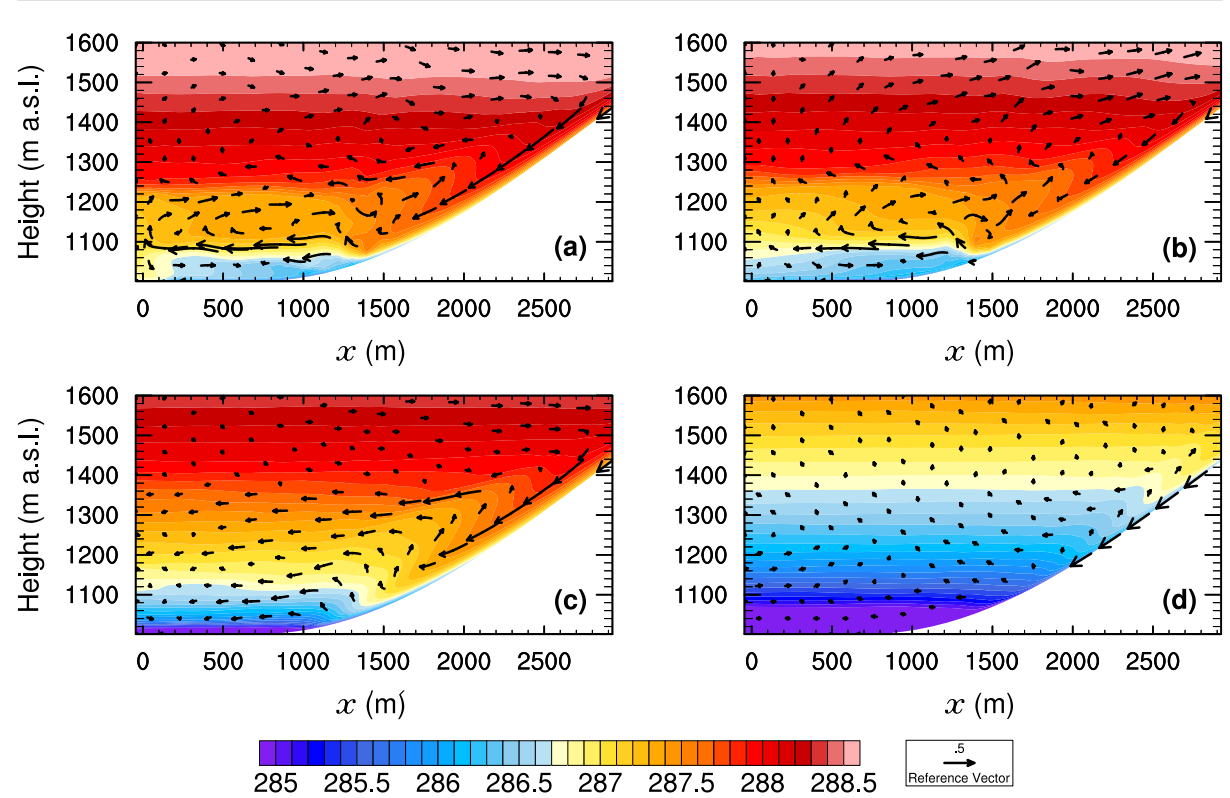

Fig. 6 Cross-valley sections (along the cross-valley direction $x$ ) of potential temperature $\theta_{v}$ averaged over the along-valley section defined by $2 \leq y \leq 4 \mathrm{~km}$ at $t=120 \mathrm{~min}[(\mathbf{a})$ and (b)] and $t=360 \mathrm{~min}[(\mathbf{c})$ and (d)] in the 3D (left) and 2D (right) valleys. The wind vectors $\mathbf{u}_{\mathbf{c r}} \equiv(u, w)$, where $u$ and $w$ are the components of the wind in the cross-valley direction $x$ and vertical direction $z$, respectively, averaged over the same along-valley section are superimposed. The reference wind vector is $0.5 \mathrm{~m} \mathrm{~s}^{-1}$.

the same (see Fig. $6 \mathrm{a}$ and $6 \mathrm{~b}$ for $t=120 \mathrm{~min}$ ). At $t=360 \mathrm{~min}$, the valley atmosphere is significantly cooler in the $2 \mathrm{D}$ valley than in the $3 \mathrm{D}$ valley (see Fig. $6 \mathrm{c}$ and $6 \mathrm{~d}$ ). This difference is closely connected to the dynamics of the valley-wind system, as discussed below.

Figure 6 suggests that, in the 3D valley, the circulation induced by the downslope flows may be subdivided in two regimes, depending on the presence of a down-valley flow or not. Before the down-valley flow is fully developed, there is a circulation within the CAP $\uparrow$, with rising motions in the centre of the valley (see Fig. $6 a$ and $6 \mathrm{~b}$ for $1200 \leq z \leq 1400 \mathrm{~m}$ ). After the down-valley flow is fully developed, a cross-valley circulation develops within the CAP $\uparrow$ (see Fig. 6c). This cross-valley circulation is not present in the 2D valley.

Close inspection of the flow features in Fig. 6c reveals that the cross-valley circulation is the result of the downslope flows overshooting their level of neutral buoyancy. This corresponds to the plume regime described by Baines (2008). In this regime, the downslope flows penetrate below their level of neutral buoyancy, transporting warmer air inside the CAP. This creates an unstable layer immediately above the downslope flows (see the potential temperature contours in Fig. $6 \mathrm{c}$, for $x \approx 2100 \mathrm{~m}$ and $z \approx 1300 \mathrm{~m}$ ), which forces upward motions, and mass conservation constrains the flow to move toward the centre of the valley.

After the valley-wind system is fully developed (after $t=180 \mathrm{~min}$ ) the downslope flows oscillate (see Fig. 7a). These oscillations result from stratification effects and the slopesurface cooling (McNider 1982). Such oscillations are not as clear in the 2D valley (see also Burns and Chemel 2015), where the speed of the downslope flows decrease as the CAP deepens. The frequency spectrum of the downslope wind speed $u_{s}$ at $10 \mathrm{~m}$ above ground level for the 3D valley shows a clear peak for a frequency $f=0.410^{-3} \mathrm{~s}^{-1}$ (see Fig. 7b), corresponding to a period $T \approx 40 \mathrm{~min}$. This frequency is close to that predicted by the model 

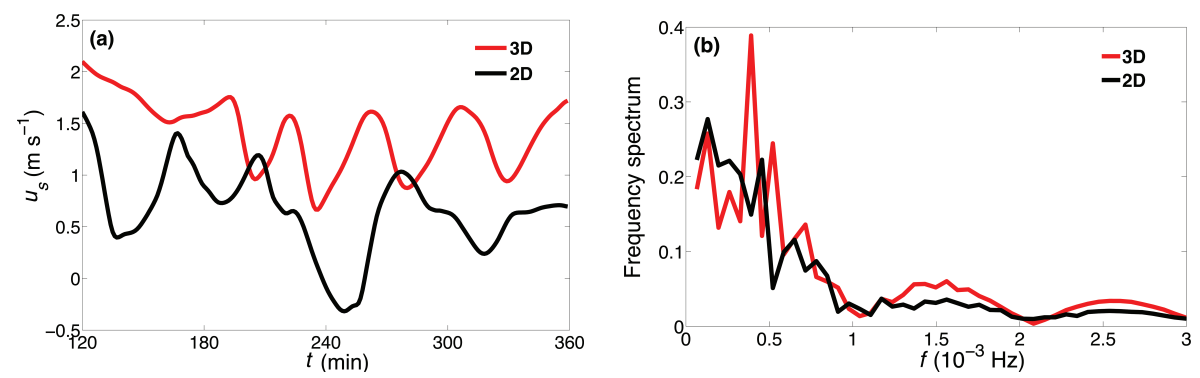

Fig. 7 (a) Time series of the downslope wind speed $u_{s}$ at $10 \mathrm{~m}$ above ground level, for $x=-1500 \mathrm{~m}$ and $y=3000 \mathrm{~m}$, for $120 \leq t \leq 360 \mathrm{~min}$ (i.e. when the downslope flows oscillate), in the 3D (red) and 2D (black) valleys. (b) Spectra $|\bar{F}|$ of $u_{s}$ at the same location, in the 3D (red) and 2D (black) valleys.

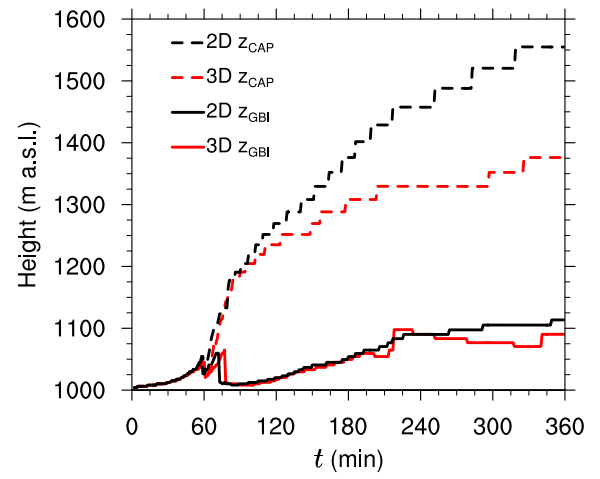

Fig. 8 Time series of the height of the groundbased inversion $z_{\mathrm{GBI}}$ (solid line) and cold-air pool $z_{\mathrm{CAP}}$ (dashed line) in the 3D (red) and 2D (black) valleys, averaged over the over the $x$ and $y$ ranges of the valley centre.

of McNider (1982), namely $f_{\text {McNider }}=N \sin \alpha /(2 \pi)$. Indeed, using $N=N_{0} \approx 0.7110^{-2} \mathrm{~s}^{-1}$ and the maximum slope angle $\alpha=\alpha_{\max } \approx 17^{\circ}$, one gets $f_{\text {McNider }} \approx 0.3310^{-3} \mathrm{~s}^{-1}$. This result is consistent with the findings of Largeron et al. (2013) for a 3D valley.

Times series of the heights of the GBI and of the CAP are displayed in Fig. 8. The heights of the CAP in the 2D and 3D valleys diverge from one another already after $1 \mathrm{~h}$ or so into the simulation, when the down-valley flow develops (see Fig. 4). It is worth noting that the growth of the CAP in the 3D valley is significantly reduced, when compared to that in the $2 \mathrm{D}$ valley, after this time, that is when vertical motions over the centre of the valley are suppressed. This result suggests that vertical advection due to slope-flow induced mass convergence over the centre of the valley is the key process controlling the growth of the CAP. The height of the GBI $z_{\mathrm{GB}}$, is similar in the 2D and 3D valleys before the down-valley flow is fully developed (after $t=180 \mathrm{~min}$ ). Later on, $z_{\mathrm{GBI}}$ decreases with time in the 3D valley, as a result of advective processes associated with the down-valley flow development. This will be discussed in the next subsections.

Figure 9 displays vertical profiles of $\overline{N^{2}}$, where the overbar indicates an average over the $x$ and $y$ ranges of the valley centre and over time intervals of $40 \mathrm{~min}$ (corresponding to that of the oscillations of the downslope flows). The stratification in the GBI is similar for both the $2 \mathrm{D}$ and $3 \mathrm{D}$ valleys with a stratification two orders of magnitude larger than the initial stratification by the end of the simulated time period (not visible on Fig. 9a and 9b). However, the temporal evolution of the stratification above the GBI is more complex for the 3D valley (see Fig. 9a) than for the 2D valley (see Fig. 9b). For the 3D valley, prior to $t=180 \mathrm{~min}$ $\overline{N^{2}}$ presents two local maxima at $z \approx 1100 \mathrm{~m}$ and $z \approx 1250 \mathrm{~m}$, which are associated with 

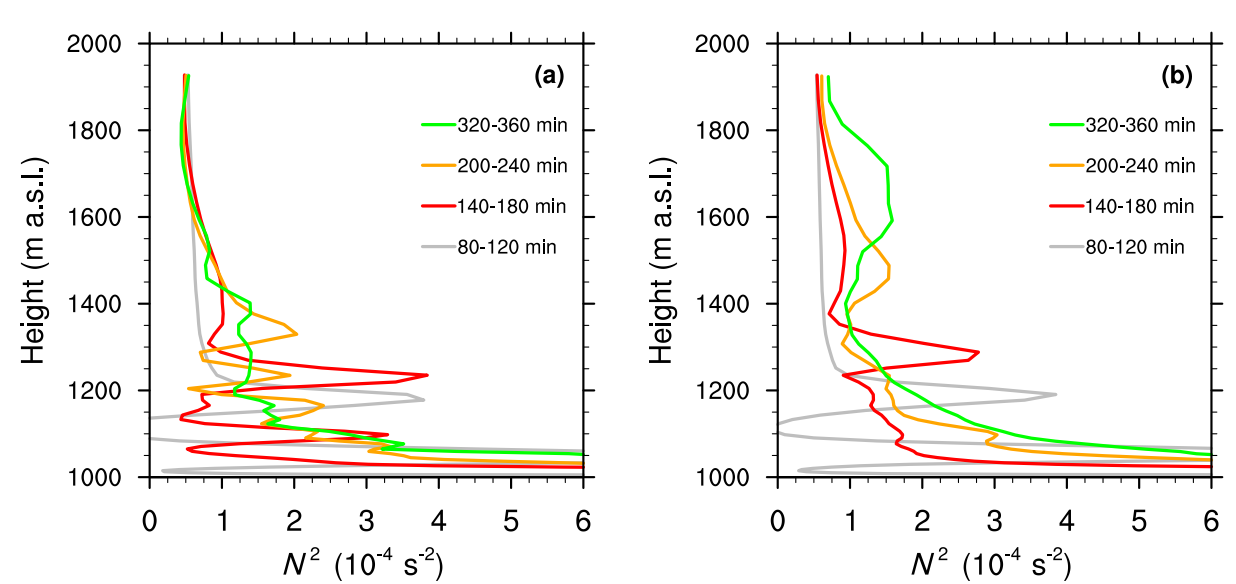

Fig. 9 Vertical profiles of the Brunt-Väisäla frequency $N^{2}$, averaged over the $x$ and $y$ ranges of the valley centre and over time intervals of $40 \mathrm{~min}$ for the $3 \mathrm{D}$ (a) and 2D (b) valleys.

the strong shear that develops over the centre of the valley because of the detrainment of the downslope flows above the GBI. After $t=180 \mathrm{~min}$, the vertical profile of $\overline{N^{2}}$ is layerized as a result of the interaction between the cross-valley circulation and the down-valley flow, which generates locally shear mixing, thereby decreasing atmospheric stability.

At the top of the CAP, a capping inversion develops in the 2D valley, largely as a result of the continuous upward transport within the CAP of air colder than the air above, and continuously increases in height with time (see Fig. $9 \mathrm{~b}$ and Fig. 8). This inversion is not as marked in the $3 \mathrm{D}$ valley by the end of the simulated time period, because it is destroyed by local shear mixing and the advection of potentially warmer air by the cross-valley circulation.

\subsection{Analysis of the time rate of change of potential temperature}

In the absence of any phase change, as is the case here, the equation for the potential temperature tendency is:

$$
\frac{\partial \theta_{v}}{\partial t}=-u_{i} \frac{\partial \theta_{v}}{\partial x_{i}}-\frac{\partial F_{i}}{\partial x_{i}}-\frac{\theta_{v}}{\rho c_{p} T} \frac{\partial R_{i}}{\partial x_{i}}
$$

where the common summation notation is used. The terms on the right-hand side (r.h.s.) represent the contributions from advection, the divergence of the SGS turbulent heat flux $\mathbf{F}$ and the divergence of the radiative flux $\mathbf{R}, c_{p}$ is the specific heat capacity at constant pressure.

Figure 10 displays vertical profiles of the potential temperature tendency $\partial \theta_{v} / \partial t$, averaged over the $x$ and $y$ ranges of the valley centre and over time intervals of $40 \mathrm{~min}$, for the $2 \mathrm{D}$ and $3 \mathrm{D}$ valleys. A striking feature is the near uniformity of the profiles with height after $t=240 \mathrm{~min}$, for both the 3D and 2D valleys. By contrast, there are large variations along the vertical before that time, which calls for an examination of the different terms contributing to the potential temperature tendency.

Vertical profiles of the different terms contributing to the potential temperature tendency (see Eq. 5), averaged in the same way as $\partial \theta_{v} / \partial t$, are presented in Fig. 11 for two time intervals. Before $t=180 \mathrm{~min}$, the advection and SGS turbulent heat flux divergence terms dominate the cooling rate (see Fig. 11a and 11b). The contributions of advection in the 2D 

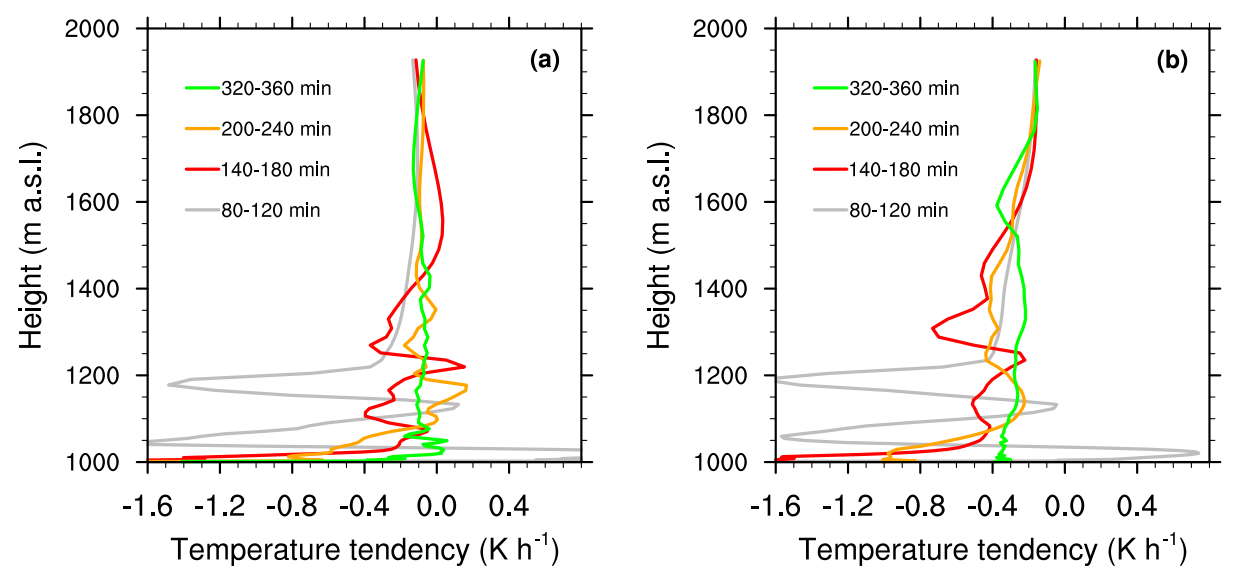

Fig. 10 Vertical profiles of potential temperature tendency $\partial \theta_{v} / \partial t$, averaged over the $x$ and $y$ ranges of the valley centre and over time intervals of $40 \mathrm{~min}$, for the $3 \mathrm{D}$ (a) and $2 \mathrm{D}$ (b) valleys.

and 3D valleys are similar, as was already qualitatively described from Fig. $6 \mathrm{a}$ and $6 \mathrm{~b}$. After $t=180 \mathrm{~min}$, the advection contribution in the 3D valley changes from a cooling to a warming as the circulation induced by the downslope flows changes (see Fig. 6c). The near uniformity of the advection contribution with height, above the GBI (of height $\approx 1100 \mathrm{~m}$ ) in the $3 \mathrm{D}$ valley may be explained as follows: the downslope flows become positively buoyant over the slope as they overshoot their level of neutral buoyancy, resulting in a spreading of the relatively warmer air vertically by convection. This relatively warmer air is then advected horizontally by the cross-valley circulation over the entire CAP. In the 2D valley, vertical motions in the centre of the valley are eventually reduced, but not suppressed (see Fig. 6d). This vertical transport produces a homogeneous cooling for $1100 \leq z \leq 1500 \mathrm{~m}$, with the contributions from advection and radiation being almost equal. Hence, the uniform cooling rate observed within the $3 \mathrm{D}$ and $2 \mathrm{D}$ valleys (above the near-surface layer) is the result of the circulations induced by the downslope flows for both valleys. Interestingly, a similar conclusion was reported for daytime conditions by Weigel et al. (2006) for the Riviera valley, and by Schmidli (2013) for a 2D idealized valley. This suggests that the effect of the thermallydriven slope flows on the vertical structure of the potential temperature tendency is similar during daytime and nighttime conditions.

Figure $11 \mathrm{a}$ and $11 \mathrm{~b}$ indicate that, until $t \approx 120 \mathrm{~min}$, the magnitude of the contribution from the SGS turbulent heat flux divergence is comparable to that of the (resolved) advection contribution up to $1250 \mathrm{~m}$ (that is the height of the CAP at $t=120 \mathrm{~min}$ ). By the end of the simulated time period, for the 3D valley, the SGS turbulent heat flux divergence contribution at the valley floor is $-2.7 \mathrm{~K} \mathrm{~h}^{-1}$, that is larger than the contributions from the other terms and larger than that for the $2 \mathrm{D}$ valley, for which the value at the valley floor is $-0.4 \mathrm{~K} \mathrm{~h}^{-1}$. This result is due to the friction induced by the down-valley wind at the ground surface. However, apart from the near-surface region, the SGS turbulent heat flux divergence contribution after $t \approx 120 \mathrm{~min}$ is very small compared to the contributions from the other terms for both the 2D and 3D valleys, over the $x$ and $y$ ranges of the valley centre (see Fig. 11c and 11d).

It should be stressed that, by considering vertical profiles horizontally averaged over the valley centre, we ignore the atmosphere above the slopes. This important point is discussed in the next section. 

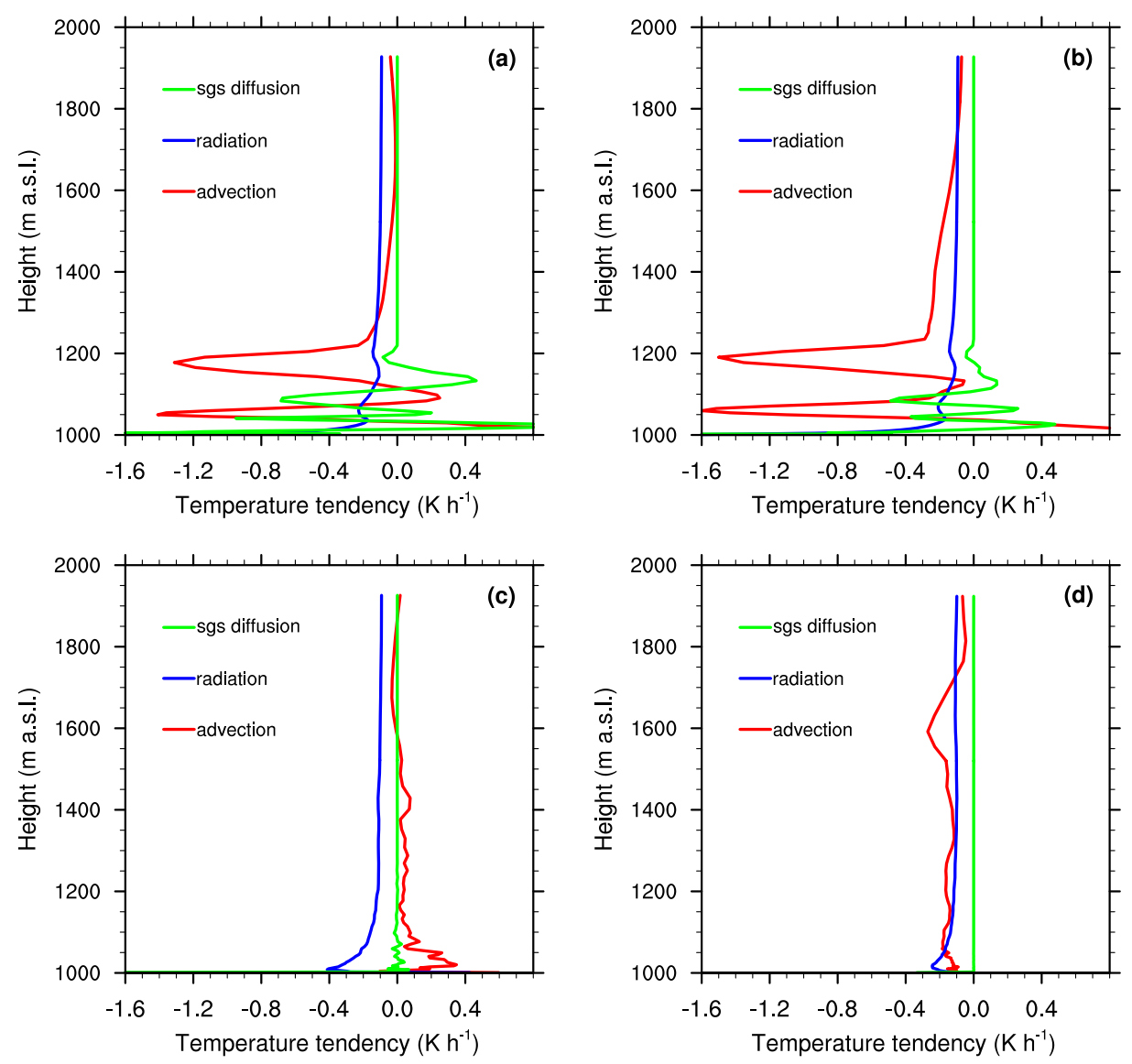

Fig. 11 Vertical profiles of the terms of the r.h.s. of Eq. 5 for the 3D (left) and 2D (right) valleys: advection (red line), radiative flux divergence (blue line) and SGS turbulent heat flux divergence (green line), averaged over the $x$ and $y$ ranges of the valley centre and over the time periods 80-120 min [(a) and (b)] and $320-360 \min [(\mathbf{c})$ and $(\mathbf{d})]$.

\subsection{Changes in the heat budget}

In this section, we examine the processes that control the evolution of the ground-based inversion layer and upper part of the valley boundary layer. Figure 12 compares time series of the different terms of Eq. 5 averaged over the GBI or CAP $\uparrow$ volumes (see Sect. 2.6 for the definition of the control volumes). Before $t \approx 120 \mathrm{~min}$, the atmosphere within the CAP $\uparrow$ experiences a rapid cooling (see Fig.12a). After this time, a transient regime develops between 120 and $270 \mathrm{~min}$ into the simulations, which is characterized by a higher cooling of the GBI compared to the CAP $\uparrow$. For the $3 \mathrm{D}$ valley, this transient regime is followed by an equilibrium regime characterized by an equal cooling rate within the GBI and the CAP $\uparrow$. By the end of the simulated time period, the cooling rates within the GBI and $\mathrm{CAP} \uparrow$ for the $2 \mathrm{D}$ valley are 3 times larger and 4 times larger, respectively, than for the 3D valley.

The presence of the down-valley flow in the $3 \mathrm{D}$ valley changes the relative importance of the processes contributing to the cooling of the valley, when compared to the $2 \mathrm{D}$ valley, as already discussed. Figure $12 \mathrm{~b}$ displays the time series of the advection contribution. For 

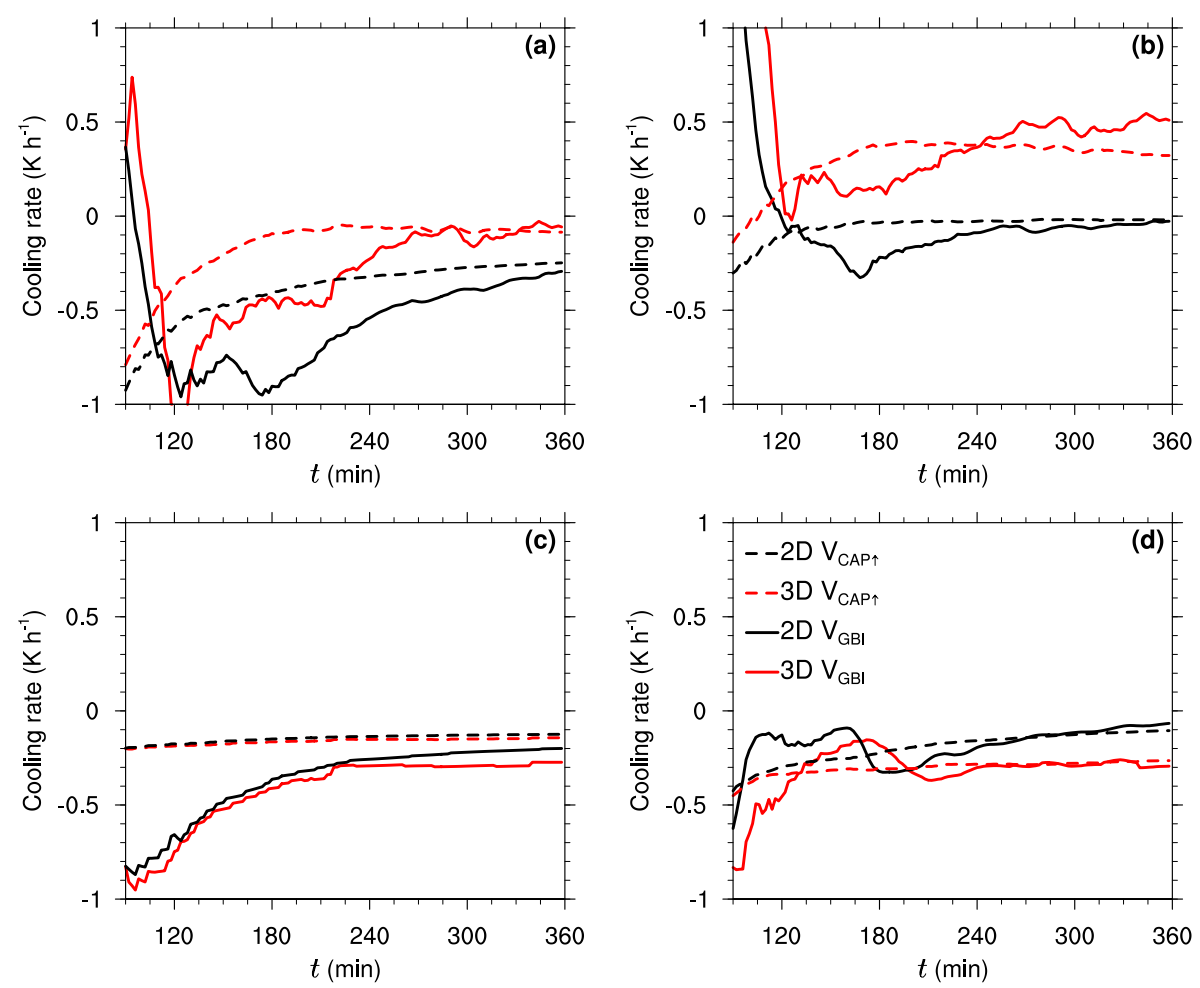

Fig. 12 Time series of the terms of the heat budget Eq. 5, volume-averaged over the GBI (solid line) or over the $\mathrm{CAP} \uparrow$ (dashed line), for the 3D (red) and the 2D (black) valleys: (a) potential temperature tendency $\partial \theta_{v} / \partial t,(\mathbf{b})$ advection, (c) radiative flux divergence, and (d) SGS turbulent heat flux divergence; see Sect. 2.6 for the definition of the control volumes.

the $2 \mathrm{D}$ valley the magnitude of the advection contribution to the cooling rate decreases with time and tends to zero by the end of the simulated period within both the GBI and CAP $\uparrow$. For the 3D valley, by contrast, the down-valley flow development leads to a warming within both the GBI and the CAP $\uparrow$; this warming is higher within the GBI than within the CAP $\uparrow$ by the end of the simulated time period.

Radiative cooling is comparable for both valleys for the entire simulated time period and within the CAP $\uparrow$ is approximately half that within the GBI (see Fig. 12c). Figure 12d displays the time series of the contribution from SGS turbulent heat flux divergence, which is mostly due to the surface turbulent heat flux. After $t \approx 180 \mathrm{~min}$, because of the slow down of the downslope flows as the CAP grows up, its magnitude decreases with time for the $2 \mathrm{D}$ valley and is almost the same within the GBI and CAP $\uparrow$. For the $3 \mathrm{D}$ valley, friction is maintained over the valley surface by the fully developed downslope and down-valley flows (after $t=180 \mathrm{~min}$ ). As a result, the contributions from SGS turbulent heat flux divergence within the GBI and $\mathrm{CAP} \uparrow$ are almost equal and nearly constant with time, and about 3 times larger than for the 2D valley. For the 3D valley, the contribution from SGS turbulent heat flux divergence within the GBI by the end of the simulated time period is of the same order of magnitude as the radiative cooling. By contrast, it is less than half the radiative cooling for the $2 \mathrm{D}$ valley. When considering the $\mathrm{CAP} \uparrow$ rather than the GBI, it is about twice the 

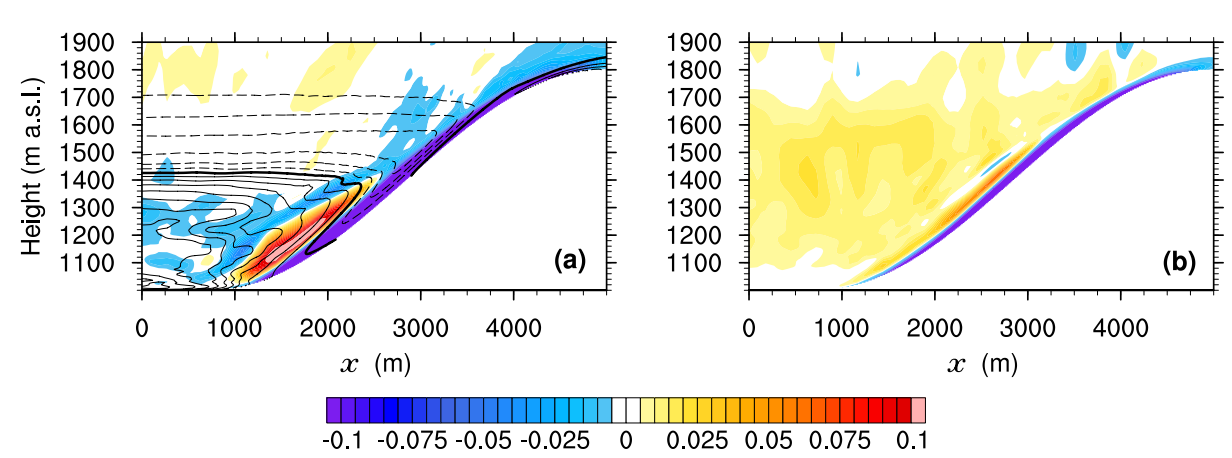

Fig. 13 Cross-valley section (along the cross-valley direction $x$ ) of the vertical velocity (colour contours) at $t=300 \mathrm{~min}$, averaged over the along-valley section defined by $2<y<4 \mathrm{~km}$ for (a) the 3D valley and (b) the $2 \mathrm{D}$ valley. The along-valley wind component $v$ (contour lines, with intervals of $0.1 \mathrm{~m} \mathrm{~s}^{-1}$ ) averaged over the same along-valley section is superimposed. Continuous lines correspond to positive values (i.e. down-valley flow), dashed lines to negative values (i.e. up-valley flow) and the thick black line corresponds to $v=0$.

radiative cooling for the $3 \mathrm{D}$ valley and is of the same order of magnitude as the radiative cooling for the $2 \mathrm{D}$ valley.

\subsection{Changes in the mass budget}

Figure 13 shows vertical cross-sections of the vertical velocity $w$, with the along-valley velocity component $v$ superimposed at $t=300 \mathrm{~min}$ for the $3 \mathrm{D}$ and $2 \mathrm{D}$ valleys. The fields are averaged over the along-valley section defined by $2<y<4 \mathrm{~km}$. The vertical velocity is a proxy for the vertical mass flux, as long as the flow is approximately incompressible (as it is in the present case). Figure $13 \mathrm{a}$ and $13 \mathrm{~b}$ suggest that the vertical mass flux is associated with the downslope flow advection for both the $2 \mathrm{D}$ and $3 \mathrm{D}$ valleys. The major difference between the 2D and 3D cases stems from the suppression of homogeneous vertical motions in the valley regions far from the slope for the 3D case. More precisely, no vertical motions are observed in the atmospheric region above the CAP $(z>1350 \mathrm{~m})$ for the 3D case. This suggests that pure downward vertical motions far from the slope layer, i.e. subsidence, play a minor role in the mass conservation within the CAP atmosphere for the $3 \mathrm{D}$ valley, for this particular setup. The importance of subsiding motions far from the slope layer with respect to the cross-valley advection in the mass budget of the CAP, can be quantified by computing the mass budget in the control volume defined horizontally by the valley centre, and of height equal to that of the CAP. Figure 14 displays time series of the net mass fluxes (defined positively outwards) associated with the three velocity components $u, v$ and $w$ across the surfaces of this volume, scaled by the mass of the CAP, for the $2 \mathrm{D}$ and the $3 \mathrm{D}$ valleys. The contribution of the vertical mass flux far from the slope layer $\left(M_{w}\right)$ to the mass budget of the $3 \mathrm{D}$ valley is much smaller than that of the cross-valley circulation $\left(M_{u}\right)$, confirming that downward vertical motions far from the slope do not play any major role in the conservation of mass within the CAP. As a consequence, the horizontal mass fluxes $M_{u}$ and $M_{v}$ have opposite (and nearly constant) values from $t=180 \mathrm{~min}$. This result also confirms that the growth of the CAP is driven by vertical advection (due to slope-flow induced mass convergence over the centre of the valley). Indeed, for the 3D valley, when $M_{w}$ becomes negative the CAP stops growing, while for the $2 \mathrm{D}$ valley the growth rate decreases with time as $M_{w}$ is reduced (see also Fig. 8). 

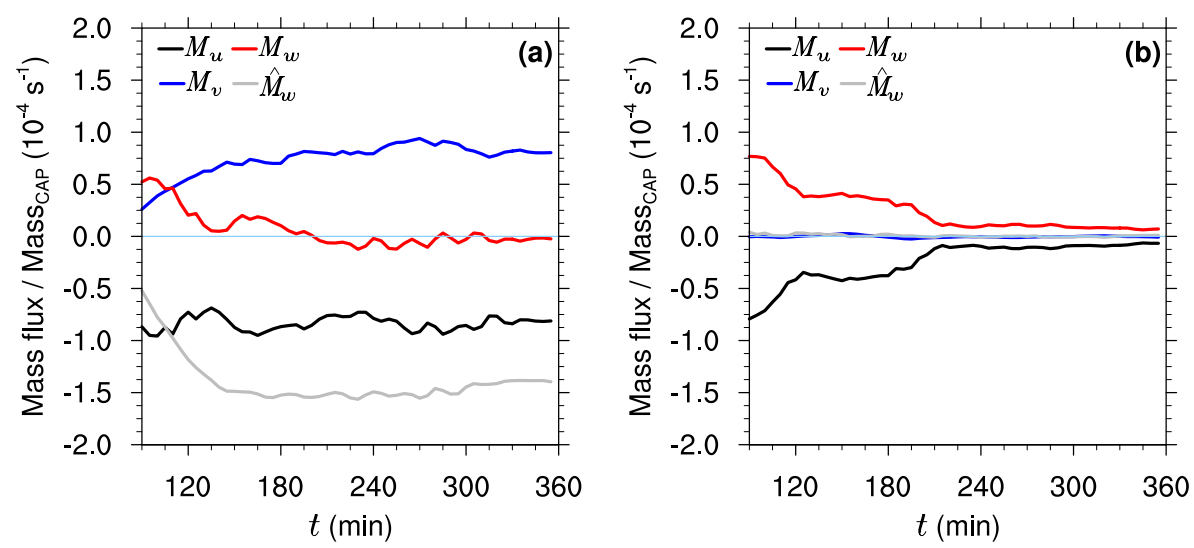

Fig. 14 Net mass fluxes across the surfaces of the control volume defined horizontally by the valley centre and of height equal to that of the CAP, scaled by the mass of the CAP: vertical flux $M_{w}$ (red), along-valley flux $M_{v}$ (blue) and cross-valley flux $M_{u}$ (black) for (a) the 3D valley and (b) the 2D valley. The grey line shows the vertical mass flux across the entire upper surface of the CAP (from slope to slope), denoted by $\hat{M}_{w}$.

While $M_{w}$ approaches zero by the end of the simulated time period for both the 2D and 3D valleys, the vertical mass flux across the entire CAP upper surface (from slope to slope, denoted by $\hat{M}_{w}$ ) for the 3D valley does not vanish (see the grey line in Fig. 14a), due to the advection of air along the slopes. This air must be replenished by air coming from other regions. Figure 13a shows that an upper-level return flow (see also Rampanelli et al. 2004) develops above the CAP for the 3D valley (see Fig. 8 for the height of the CAP). This return flow transports air from the plain to the valley, as opposed to the down-valley flow underneath. Hence, for the 3D case the inflow of air into the slope layer, is driven by a combination of the return flow, the subsidence above the plateaux and the horizontal (cross-valley) advection from the plateaux.

The relative contributions of these processes to the mass budget of the $3 \mathrm{D}$ valley can be quantified by considering the mass budget for a control volume encompassing the upper part of the valley atmosphere and part of the plateaux, defined by $z_{\mathrm{CAP}}<z<\left(h_{0}+H+100 \mathrm{~m}\right)$, $-\left(S_{x}+L_{x}+1000 \mathrm{~m}\right)<x<\left(S_{x}+L_{x}+1000 \mathrm{~m}\right)$ and $2<y<4 \mathrm{~km}$. Figure 15 displays time series of the net mass fluxes associated with the horizontal velocity components $u$ and $v$, and the mass fluxes associated with the vertical velocity $w$ across the top and bottom surfaces of this control volume, denoted by $\hat{M}_{u}, \hat{M}_{v}, \hat{M}_{w, \mathrm{t}}$ and $\hat{M}_{w}$, respectively. We quantify the importance of each of these terms in the mass budget with respect to $\hat{M}_{w}$ by normalizing them by $\hat{M}_{w}$. Before $t=285 \mathrm{~min}$, the subsidence from the free atmosphere $\left(\hat{M}_{w, \mathrm{t}}\right)$ decreases monotonically in absolute value with time. The along-valley mass flux $\left(\hat{M}_{v}\right)$ decreases continuously and becomes negative from about $t=160 \mathrm{~min}$, as the return flow intensifies. After $t=160 \mathrm{~min}, \hat{M}_{v}$ increases monotonically in absolute value with a value of $-0.75 \hat{M}_{w}$ at $t=285 \mathrm{~min}$. At this time, the advection of air along the slopes, across the upper surface of the CAP, is mainly replenished by the air from the plain, due to the return flow. After this time, $\hat{M}_{w, \mathrm{t}}$ increases in absolute value, which is associated with a decrease in absolute value of $\hat{M}_{v}$. By the end of the simulated time period, $\hat{M}_{w, \mathrm{t}}$ is equal to $-0.35 \hat{M}_{w}$ and $\hat{M}_{u}$ to $-0.15 \hat{M}_{w}$, while $\hat{M}_{v}$ is equal to $-0.50 \hat{M}_{w}$. Hence, we conclude that, by the end of the simulated time period, the vertical mass flux in the slope layer is driven by a complex interplay between the along-valley mass flux from the plain to the valley, resulting from the return flow, and the subsidence and horizontal advection from the plateaux. 


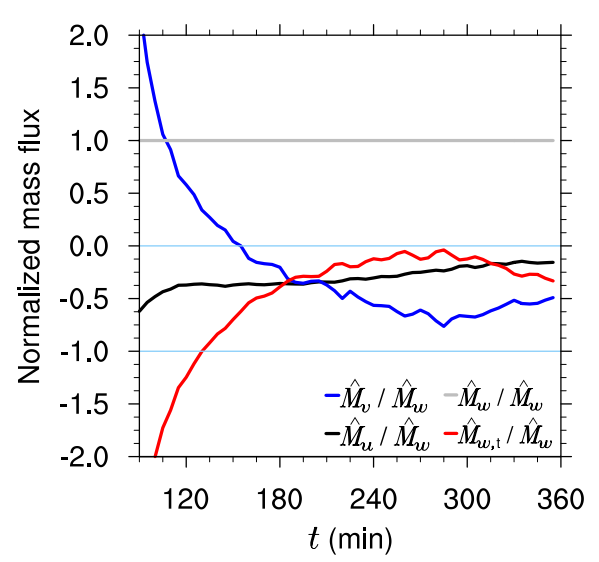

Fig. 15 Mass fluxes across the surfaces of the upper control volume defined by $z_{\mathrm{CAP}}<z<\left(h_{0}+H+\right.$ $100 \mathrm{~m}),-\left(S_{x}+L_{x}+1000 \mathrm{~m}\right)<x<\left(S_{x}+L_{x}+\right.$ $1000 \mathrm{~m}), 2<y<4 \mathrm{~km}$, normalized by the vertical mass flux across the bottom surface, denoted $\hat{M}_{w}$ : net along-valley flux $\hat{M}_{v} / \hat{M}_{w}$ (blue), net cross-valley flux from the plateaux $\hat{M}_{u} / \hat{M}_{w}$ (black), vertical flux across the bottom surface (within the CAP) $\hat{M}_{w} / \hat{M}_{w}$ (grey), vertical flux across the top surface (subsidence) $\hat{M}_{w, \mathrm{t}} / \hat{M}_{w}$ (red), for the $3 \mathrm{D}$ valley.

\section{Sensitivity to the length of the valley}

The previous discussion shows that the flow characteristics depends on the time when the quasi-steady state is reached and the down-valley flow is fully developed, denoted by $T_{\mathrm{ss}}$. By changing the length of the valley, we expect $T_{\mathrm{ss}}$ to vary. Schmidli and Rotunno (2015) suggested that, assuming constant forcing (i.e. a constant surface sensible heat flux), $T_{\mathrm{ss}}$ is proportional to $T_{\ell}=2 L_{\mathrm{tot}} /\left(H N_{0}\right)$, with a coefficient of proportionality of about $3 . T_{\ell}$ is the timescale associated with the linear wave solution of the along-valley wind equations derived by Egger (1990). To examine this proportionality and the sensitivity of the flow characteristics to the valley length, an additional simulation was performed by changing $L_{\mathrm{tot}}$ only, from 11 to $15 \mathrm{~km}$. Table 1 summarizes the main variables analyzed for the different valley lengths $L_{\text {tot }}$, including that of the $2 \mathrm{D}$ valley, which is infinite.

The coefficient of proportionality between $T_{\mathrm{ss}}$ and $T_{\ell}$ is 2.8 for the two valley lengths considered, and therefore is about 3 as was suggested by Schmidli and Rotunno (2015). Since for the simulations considered $H$ and $N_{0}$ are constant as is the ratio $T_{\mathrm{ss}} / T_{\ell}, T_{\mathrm{ss}}$ should vary in proportion to $L_{\mathrm{tot}}$, as confirmed from Table 1 . This shows that $T_{\ell}$ is the relevant timescale for the approach to the quasi-steady state. The longer is the valley, the longer is the time before the quasi-steady state is reached and a cross-valley circulation is established. This results in a more gradual transition from the $2 \mathrm{D}$ regime and the $3 \mathrm{D}$ regime and therefore a deeper CAP. Note however that the change of the valley length has no significant effect on $z_{\mathrm{GBI}}, u_{s, \max }$ and the volume-averaged temperatures $\left(\left\langle\theta_{v}\right\rangle_{\mathrm{GBI}}\right.$ and $\left\langle\theta_{v}\right\rangle_{\mathrm{CAP} \uparrow}$ in Table 1).

Table 1 also shows that the deeper the valley boundary layer, the stronger the downvalley wind jet at the same distance from the valley exit. This can be explained by the Bernoulli model discussed in Sect. 3.3 and using hydrostatic balance. Writing each of the flow variable as the sum of a reference value (denoted by a subscript $r$ ), and a deviation from this reference value (denoted by a prime), hydrostatic balance within the CAP can be written as

$$
\partial p^{\prime} / \partial z=-\left(\rho_{\mathrm{r}} / \theta_{\mathrm{r}}\right) \theta_{v}^{\prime} g
$$

where $\rho_{\mathrm{r}}$ and $\theta_{\mathrm{r}}$ are the reference density and potential temperature, respectively, outside of the CAP, and the usual approximation $-\rho^{\prime} / \rho_{\mathrm{r}}=\theta_{v}^{\prime} / \theta_{\mathrm{r}}$ is used since density variations due to pressure changes are small compared to those due to potential temperature changes (see for instance Holton 2004, pp. 198-199). Integrating Eq. (6) from the valley floor altitude, 
Table 1 Effect of the valley length on the variables discussed in Sect. 5, namely: the total valley length $L_{\text {tot }}$; the time when the quasi-steady state is reached $T_{\mathrm{Ss}}$; the ratio $T_{\mathrm{ss}} / T_{\ell}$, where $T_{\ell}$ is the timescale associated with of the along-valley wind (see text for details)); the along-valley wind speed at the distance $y=L_{y}-S_{y}-2 \mathrm{~km}$ from the valley exit, for $z=20 \mathrm{~m}$ and averaged over $\left[-L_{x}, L_{x}\right]$ in the cross-valley direction, denoted by $v_{2}$; the maximum downslope wind component $u_{s}$, max at $y=3 \mathrm{~km}$; the height of the ground-based inversion $z_{\mathrm{GBI}}$ and of the cold-air pool $z_{\mathrm{CAP}}$, calculated as in Fig. 8; and the volume-averaged potential temperature within the GBI and $\mathrm{CAP} \uparrow$, denoted by $\left\langle\theta_{v}\right\rangle_{\mathrm{GBI}}$ and $\left\langle\theta_{v}\right\rangle_{\mathrm{CAP} \uparrow}$, respectively. The values of the last six variables were computed at $t=360 \mathrm{~min}$.

\begin{tabular}{lllllllll}
\hline $\begin{array}{l}L_{\mathrm{tot}} \\
(\mathrm{km})\end{array}$ & $\begin{array}{l}T_{\mathrm{Ss}} \\
(\mathrm{min})\end{array}$ & $T_{\mathrm{Ss}} / T_{\ell}$ & $\begin{array}{l}v_{2} \\
\left(\mathrm{~m} \mathrm{~s}^{-1}\right)\end{array}$ & $\begin{array}{l}u_{s, \max } \\
\left(\mathrm{m} \mathrm{s}^{-1}\right)\end{array}$ & $\begin{array}{l}z_{\mathrm{GBI}} \\
(\mathrm{m})\end{array}$ & $\begin{array}{l}z_{\mathrm{CAP}} \\
(\mathrm{m})\end{array}$ & $\begin{array}{l}\left\langle\theta_{v}\right\rangle_{\mathrm{GBI}} \\
(\mathrm{K})\end{array}$ & $\begin{array}{l}\left\langle\theta_{v}\right\rangle_{\mathrm{CAP} \uparrow} \\
(\mathrm{K})\end{array}$ \\
\hline 11 & 180 & 2.8 & 2.2 & 2.45 & 1090 & 1376 & 285.8 & 287.2 \\
15 & 250 & 2.8 & 3.4 & 2.48 & 1098 & 1430 & 285.6 & 287.2 \\
$\infty$ & $\infty$ & $\infty$ & 0 & 1.60 & 1113 & 1554 & 284.6 & 286.6 \\
\hline
\end{tabular}

$h_{0}$, to the height of the CAP, $z_{\mathrm{CAP}}$, yields

$$
p^{\prime}=\rho_{\mathrm{r}} \int_{h_{0}}^{z_{\mathrm{CAP}}} \frac{g}{\theta_{\mathrm{r}}} \theta_{v}^{\prime} d z+p^{\prime}\left(z=z_{\mathrm{CAP}}\right)=\rho_{\mathrm{r}} \frac{g}{\theta_{\mathrm{r}}} \overline{\theta_{v}^{\prime}} d_{\mathrm{CAP}}+p^{\prime}\left(z=z_{\mathrm{CAP}}\right),
$$

where $\overline{\theta_{v}^{\prime}}$ is the layer-averaged potential temperature deficit across the depth of the CAP $d_{\mathrm{CAP}}=z_{\mathrm{CAP}}-h_{0}$. We now consider Eq. 4 ; by assuming that $\rho_{1} \approx \rho_{2} \approx \rho_{\mathrm{r}}$ (that is density variations are only important in the buoyancy term, i.e. the fluid is Boussinesq), Eq. 4 becomes

$$
v_{2}^{2}-v_{1}^{2}=\frac{2}{\rho_{\mathrm{r}}}\left(p_{1}^{\prime}-p_{2}^{\prime}\right),
$$

where the subscripts 1 and 2 refer to a position within the valley and at the valley exit. As in Sect. $3.3 v_{2}$ will be denoted as $v_{\text {exit }}$. Using hydrostatic balance written in the form of Eq. 7, the difference between the squared down-valley wind speed for two valleys of different length may be computed by subtracting Eq. (8) for the two valleys. Assuming that the pressure at the valley exit is the same in the two valleys and that the down-valley wind speed within the valley is almost the same (as it is in the present case), we obtain

$$
\Delta v_{\mathrm{exit}}^{2}=2 \frac{g}{\theta_{\mathrm{r}}} \overline{\theta_{v}^{\prime}} \Delta z_{\mathrm{CAP}},
$$

where we have also assumed that the potential temperature variations averaged over the depth of the CAP $\left(\overline{\theta_{v}^{\prime}}\right)$ and the pressure perturbations at the top of the CAP $\left[p^{\prime}\left(z=z_{\mathrm{CAP}}\right)\right]$ are the same within the two valleys (as is the case here, not shown). $\Delta v_{\text {exit }}^{2}$ and $\Delta z_{\mathrm{CAP}}$ are the differences in the squared along-valley speed at the valley exit and in the height of the CAP between the two valleys, respectively.

Figure 16 shows the comparison between the squared wind speed difference computed using Eq. 9 (denoted by $\Delta v_{\text {exit }}^{2}$ ) with the variables averaged in the range $2<y<4 \mathrm{~km}$, and from the WRF model outputs (denoted by $\Delta v_{\mathrm{WRF}}^{2}$ ) at the valley exit ( $y=9 \mathrm{~km}$ and $y=13 \mathrm{~km}$ for the shorter and longer valley, respectively). The comparison is made between 150 and $360 \mathrm{~min}$. Despite the assumptions made to derive Eq. 9, this expression is remarkably accurate: $74 \%$ of the values for $\Delta v_{\mathrm{WRF}}^{2}$ are within a factor of 2 of the counterpart values for $\Delta v_{\text {exit }}^{2}$. It should be noted that Eq. 9 provides an expression for the difference in the squared along-valley wind speed between two finite length valleys, provided that $\Delta z_{\mathrm{CAP}}$ is known. This means that an equation for $\Delta z_{\mathrm{CAP}}$ is still required. 


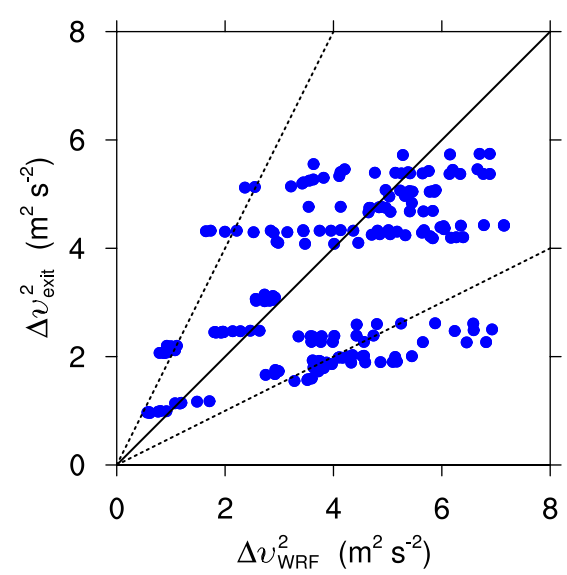

Fig. 16 Scatter plot of the difference in the squared along-valley wind speed between the two finite length valleys displayed in Table 1 , computed from the WRF model outputs ( $x$-axis, $\left.\Delta v_{\mathrm{WRF}}^{2}\right)$ versus its estimate, using Eq. 9 (y-axis, $\Delta v_{\text {exit }}^{2}$ ), between 150 and $360 \mathrm{~min}$. The dashed lines indicate the range within a factor 2 and the solid line is the one-to-one line.

Even though the CAP is deeper in the longer valley, the maximum speed of the downslope flows at the end of the simulation hardly varies, and a steady state is reached, after $T_{\mathrm{ss}}$. Furthermore the cross-valley circulation and the structure of the CAP present the same characteristics. To conclude, the mechanisms that control the structure of the CAP and its evolution are independent of the valley length as soon as the down-valley flow is fully developed.

\section{Conclusions}

We have characterized the influence of a thermally-driven down-valley flow on a developing cold-air pool in an idealized alpine valley under decoupled conditions. Results from numerical model simulations of a developing cold-air pool in a 3D valley, which allows for the formation of a down-valley flow, and in a 2D valley, where the formation of a down-valley flow is inhibited, were analyzed and compared. The main conclusions, along with some discussion, are given below.

- Before the development of the down-valley flow, the thermodynamics of the valley atmosphere in the $3 \mathrm{D}$ valley is similar to that in the $2 \mathrm{D}$ valley. The downslope flows induce upward motions in the centre of the valley, which are responsible for the growth of the cold-air pool (CAP). As shown by Catalano and Cenedese (2010) and Katurji and Zhong (2012), the depth of the valley is also a key factor controlling the growth of the CAP. Shallower valleys will be 'filled' more rapidly by the developing CAP, suppressing the effect of the downslope flows on the valley atmosphere.

- The down-valley flow, which forms as a result of the differential cooling between the valley and the plain, is fully developed after a time period that increases with the valley length. After this time, the down-valley flow reaches a quasi-steady state characterized by a balance between the pressure force and advection in the along-valley direction. It then behaves as 'a flow in a pipe', with the cross-sectional area of the pipe set by the depth of the CAP. The value of the down-valley wind speed at the valley exit during the steady-state appears to be well predicted by the Bernoulli equation. The time when the quasi-steady state is reached is found to be about $3 T_{\ell}$, where $T_{\ell}=2 L_{\text {tot }} /\left(H N_{0}\right), L_{\text {tot }}$ is the total valley length, $H$ is the valley depth, and $N_{0}$ is the initial Brunt-Väisäla frequency (see also Schmidli and Rotunno 2015). 
- In the 2D valley, as the CAP deepens and engulfs the slopes, the downslope flows retreat back up the slopes and slow down. This is not the case in the 3D valley. When the downvalley flow forms, vertical motions induced by the downslope flows cease, and a crossvalley circulation develops as a result of the downslope flow advection within the CAP. Hence, the growth of the CAP is reduced in the $3 \mathrm{D}$ valley, the capping inversion at its top is not as marked as in the $2 \mathrm{D}$ valley and the valley atmosphere is warmer than that for the $2 \mathrm{D}$ valley. This result has implications for the dilution of pollutants. Indeed, pollutants emitted at the valley floor will be spread in the horizontal by the down-valley flow, as was observed for instance by Gudiksen and Shearer (1989) from field measurements, instead of being diluted throughout the CAP as for a $2 \mathrm{D}$ valley configuration (e.g. Chemel and Burns 2015).

- Even though the 2D valley atmosphere is cooler than that of the 3D valley, the stability of the CAP is similar for both valleys. By the end of the simulated time period, the net cooling rate is uniform in the vertical throughout the upper part of the CAP, above the near-surface layer, for both the $3 \mathrm{D}$ and $2 \mathrm{D}$ valleys. This prevents the stability of the upper part of the CAP from increasing with time for both valleys. However, the processes involved are different. While radiative flux divergence leads to a cooling in both valleys, advection leads to a cooling in the $2 \mathrm{D}$ valley and a warming in the $3 \mathrm{D}$ valley. These processes are found uniform in the vertical throughout the upper part of the CAP for both the $3 \mathrm{D}$ and $2 \mathrm{D}$ valleys, thereby explaining the uniformity of the net cooling rate in the vertical. Near-surface cooling from subgrid-scale turbulence flux divergence is greatly enhanced for the 3D valley (by more than a factor 6 over the valley centre). Our results may explain the findings of De Wekker and Whiteman (2006) as regards the time scale for nocturnal cooling, defined as the time when $\approx 63 \%$ (namely $1-e^{-1}$ ) of the total cumulative nocturnal cooling over one night has occurred, assuming an exponential decay for this quantity. It was found by these authors that, for different basins, valleys and plains, this time scale is in the range 3 to $6 \mathrm{~h}$, depending on the geometry of the basin or valley being considered. This range may be related to the time when cooling by advection is suppressed by the developing down-valley flow, or is gradually being suppressed by the developing CAP (as for the $2 \mathrm{D}$ valley).

- When considering the CAP volume, the mass budget of the 3D valley is largely driven by a balance between the divergence of the down-valley flow in the along-valley direction and the convergence of the downslope flows at the top of the CAP. The net contribution from downward vertical motions to the mass budget far from the slopes is found negligible for the 3D valley. When considering the entire valley scale, the return flow above the CAP (flowing from the plain to the valley) plays a non-negligible role in the mass budget. Indeed, the vertical mass flux at the top of the CAP is driven by an interplay between the along-valley convergence of the return flow and the subsiding or horizontal convergent motions from the plateau regions. It should be noted that the computation of the mass budget in previous work relied on the hypothesis of horizontally-homogeneous subsidence from the free atmosphere above the CAP, therefore neglecting the feedback of the down-valley flow on the downslope flows (Whiteman and Barr 1986). The results of the present paper suggest that unlike daytime situations (Rampanelli et al. 2004; Weigel et al. 2006), mass conservation does not imply subsidence over the valley centre during the night.

- The mechanisms that control the structure of the CAP and its evolution are independent of the valley length as soon as the quasi-steady state is reached and the down-valley flow is fully developed. 
This work has described the interactions that take place between the nighttime valleywind system and a developing cold-air pool. Even though the physical mechanisms presented above are found to be independent of the length of the valley, there are a number of other parameters that may affect the results (e.g., the geometry of the valley, the land cover, the stratification) and remain to be examined.

Acknowledgements This work has been supported by a PhD grant provided by the LabEx Osug@2020 (Investissements d'avenir - ANR10LABX56) in Grenoble and by the University of Hertfordshire. Numerical simulations were run on the French national HPC facilities at CINES. Finally, the authors thank the referees for valuable comments, which led to substantial improvements in this paper.

\section{References}

Baines PG (2008) Mixing in downslope flows in the ocean - plumes versus gravity currents. Atmos Ocean 46:405-419

Baker KR, Simon H, Kelly JT (2011) Challenges to modeling "cold pool" meteorology associated with high pollution episodes. Environ Sci Technol 45:7118-7119

Banta RM, Darby LS, Fast JD, Pinto JO, Whiteman CD, Shaw WJ, Orr BW (2004) Nocturnal low-level jet in a mountain basin complex. Part I: evolution and effects of local flows. J Appl Meteorol 43:1348-1365

Bou-Zeid E, Meneveau C, Parlange M (2004) A scale-dependent Lagrangian dynamic model for large eddy simulation of complex turbulent flows. Phys Fluids 17, doi: 10.1063/1.1839152

Burns P, Chemel C (2014) Evolution of cold-air-pooling processes in complex terrain. Boundary-Layer Meteorol 150:423-447

Burns P, Chemel C (2015) Interactions between downslope flows and a developing cold-air pool. BoundaryLayer Meteorol 154:57-80

Catalano F, Cenedese A (2010) High-resolution numerical modeling of thermally driven slope winds in a valley with strong capping. J Appl Meteorol Climatol 49:1859-1880

Chemel C, Burns P (2015) Pollutant dispersion in a developing valley cold-air pool. Boundary-Layer Meteorol 154:391-408

Chen F, Dudhia J (2001) Coupling an advanced land-surface/hydrology model with the Penn State/NCAR MM5 modeling system. Part I: model implementation and sensitivity. Mon Weather Rev 129:569-585

Cuxart J (2015) When can a high-resolution simulation over complex terrain be called les? Front Earth Sci 3:87

De Wekker SFJ, Whiteman CD (2006) On the time scale of nocturnal boundary layer cooling in valleys and basins and over plains. J Appl Meteorol Climatol 45:813-820

Dudhia J (1989) Numerical study of convection observed during the winter monsoon experiment using a mesoscale two-dimensional model. J Atmos Sci 46:3077-3107

Egger J (1990) Observations of thermally developed wind systems in mountainous terrain. In: Blumen W (ed) Atmospheric processes over complex terrain, Meteorological Monographs, vol 23, no. 45, American Meteorological Society, 45 Beacon St., Boston, MA, USA, chap 3, pp 43-58

Gudiksen PH, Shearer DL (1989) The dispersion of atmospheric tracers in nocturnal drainage flows. J Appl Meteorol 28:602-608

Holton JR (2004) An introduction to dynamic meteorology (4th edition). Elsevier Academic Press, Burlington, MA, USA, chap 7, pp 198-199

Katurji, Zhong (2012) The influence of topography and ambient stability on the characteristic of cold-air pools: a numerical investigation. J Appl Meteorol Climatol 51:1740-1749

Klemp JB, Dudhia J, Hassiotis J (2008) An upper gravity-wave absorbing layer for NWP applications. Mon Weather Rev 136:3987-4004

Lareau N, Horel J (2015) Dynamically induced displacements of a persistent cold-air pool. BoundaryLayer Meteorol 154:291-316

Largeron Y (2010) Dynamique de la couche limite atmosphérique stable en relief complexe. Application aux épisodes de pollution particulaire des vallées alpines. PhD thesis, Université de Grenoble, France, $<$ tel-00606115>

Largeron Y, Staquet C, Chemel C (2013) Characterization of oscillatory motions in the stable atmosphere of a deep valley. Boundary-Layer Meteorol 148:439-454

Łobocki L (2014) Surface-layer flux-gradient relationships over inclined terrain derived from a local equilibrium, turbulence closure model. Boundary-Layer Meteorol 150:469-483 
McNider RT (1982) A note on velocity fluctuations in drainage flows. J Atmos Sci 39:1658-1660

Mlawer EJ, Taubman SJ, Brown PD, Iacono MJ, Clough SA (1997) Radiative transfer for inhomogeneous atmospheres: RRTM, a validated correlated-k model for the longwave. J Geophys Res 102:663-682

Nadeau DF, Pardyjak ER, Higgins CW, Huwald H, Parlange MB (2012) Flow during the evening transition over steep alpine slopes. Q J R Meteorol Soc 139:607-624

Neff WD, King CW (1987) Observations of complex terrain flows using acoustic sounders: experiments, topography and winds. Boundary-Layer Meteorol 40:363-392

Neff WD, King CW (1989) The accumulation and pooling of drainage flows in a large basin. J Appl Meteorol 28:518-529

O'Steen LB (2000) Numerical simulation of nocturnal drainage flows in idealized valley-tributary system. J Appl Meteorol 39:1845-1860

Pinto JO, Parsons DB, Brown WOJ, Cohn S, Chamberlain N, Morley B (2006) Coevolution of down-valley flow and the nocturnal boundary layer in complex terrain. J Appl Meteorol Climatol 45:1429-1449

Rampanelli G, Zardi D, Rotunno R (2004) Mechanism of up-valley winds. J Atmos Sci 61:3097-3111

Schmidli J (2013) Daytime heat transfer processes over mountainous terrain. J Atmos Sci 70:4041-4066

Schmidli J, Rotunno R (2010) Mechanism of along-valley winds and heat exchange over mountainous terrain. J Atmos Sci 67:3033-3047

Schmidli J, Rotunno R (2015) The quasi-steady state of the valley wind system. Front Earth Sci 3:79

Schmidli J, Poulos GS, Daniels MH, Chow FK (2009) External influences on nocturnal thermally driven flows in a deep valley. J Appl Meteorol Climatol 48:3-23

Schmidli J, Billings B, Chow FK, De Wekker SFJ, Doyle J, Grubišić V, Holt T, Jiang Q, Lundquist KA, Sheridan P, Vosper S, Whiteman CD, Wyszogrodzki AA, Zängl G (2011) Intercomparison of mesoscale model simulations of the daytime valley wind system. Mon Weather Rev 139:1389-1409

Serafin S, Zardi D (2011) Daytime development of the boundary layer over a plain and in a valley under fair weather conditions: a comparison by means of idealized numerical simulations. J Atmos Sci 68:21282141

Skamarock WC, Klemp JB, Dudhia J, Gill DO, Barker DM, Duda MG, Huang XY, Wang W, Powers JG (2008) A Description of the Advanced Research WRF Version 3. NCAR Technical Note NCAR/TN475+STR, NCAR, Boulder, CO, USA, $125 \mathrm{pp}$

Smith CM, Porté-Agel F (2014) An intercomparison of subgrid models for large-eddy simulation of katabatic flows. Q J R Meteorol Soc 140:1294-1303

Vergeiner I, Dreiseitl E (1987) Valley winds and slope winds - Observations and elementary thoughts. Meteorol Atmos Phys 36:264-286

Vinokur M (1980) On one-dimensional stretching functions for finite-difference calculations. NASA Contractor Report 3313, NASA, Washington, DC, USA, $56 \mathrm{pp}$

Vosper SB, Brown AR (2008) Numerical simulations of sheltering in valleys: the formation of nighttime cold-air pools. Boundary-Layer Meteorol 127:429-448

Vosper SB, Hughes JK, Lock AP, Sheridan PF, Ross AN, Jemmett-Smith B, Brown AR (2014) Cold-pool formation in a narrow valley. Q J R Meteorol Soc 140:699-714

Weigel AP, Chow FK, Rotach MW, Street RL, Xue M (2006) High-resolution large-eddy simulations of flow in a steep Alpine valley. Part II: flow structure and heat budgets. J Appl Meteorol Climatol 45:87-107

Whiteman CD (1990) Observations of thermally developed wind systems in mountainous terrain. In: Blumen W (ed) Atmospheric processes over complex terrain, Meteorological Monographs, vol 23, no. 45, American Meteorological Society, 45 Beacon St., Boston, MA, USA, chap 2, pp 5-42

Whiteman CD, Barr S (1986) Atmospheric mass transport by along-valley wind systems in a deep Colorado valley. J Climate Appl Meteor 25:1205-1212

Wicker LJ, Skamarock WC (2002) Time-splitting methods for elastic models using forward time scheme. Mon Weather Rev 130:2088-2097

Zängl G (2004) A reexamination of the valley wind system in the Alpine Inn Valley with numerical simulations. Meteorol Atmos Phys 87:241-256

Zängl G (2005) Formation of extreme cold-air pools in elevated sinkholes: an idealized numerical process study. Mon Weather Rev 133:925-941

Zardi D, Whiteman CD (2013) Diurnal mountain wind systems. In: Chow FK, De Wekker SFJ, Snyder BJ (eds) Mountain weather research and forecasting: recent progress and current challenges, Springer Atmospheric Sciences, Springer, New York, NY, USA, chap 2, pp 35-119 